\title{
Distinctive properties of cones in the retinal clock and the circadian system
}

Cristina Sandu ${ }^{1 * \#}$, Prapimpun Wongchitrat ${ }^{2 *}$, Nadia Mazzaro $^{1}$, Catherine Jaeger $^{1}$, Hugo Calligaro $^{1}$, Jorge Mendoza ${ }^{1}$, David Hicks ${ }^{1}$, Marie-Paule Felder-Schmittbuhl ${ }^{1 \#}$

1 Centre National de la Recherche Scientifique, Université de Strasbourg, Institut des Neurosciences Cellulaires et Intégratives, 67084 Strasbourg, France

${ }^{2}$ Center for Research and Innovation, Faculty of Medical Technology, Mahidol University, 73170 Salaya, Nakon Pathom, Thailand

${ }^{*}$ Equal contribution

\# Corresponding authors : feldermp@inci-cnrs.unistra.fr (tel +33 $388 \quad 4566$ 44); sandu@inci-cnrs.unistra.fr (tel +33 3884566 53).

ORCID: Cristina Sandu 0000-0001-8836-5837; Prapimpun Wongchitrat 0000-0001-70093028; Catherine Jaeger 0000-0001-8519-8893; Hugo Calligaro 0000-0003-0334-6974; Jorge Mendoza 0000-0003-2819-9624; Marie-Paule Felder-Schmittbuhl 0000-0003-3539-1243.

\section{Acknowledgements}

This work was funded by Retina France and the University of Strasbourg Institute of Advanced Studies, as well as fellowships from Fondation Servier and ISN-CAEN to PW. We thank Dr. Dominique Sage, Dr. Sophie Reibel and Nicolas Lethenet from Chronobiotron UMS 3415 (Strasbourg, France) for animal care, Dr. Anand Swaroop for the $\mathrm{Nrl} \mathrm{KO}$ mice and Daniel Clesse for HPLC measurements. 


\section{Abstract}

Multiple circadian clocks dynamically regulate mammalian physiology. In retina, rhythmic gene expression serves to align vision and tissue homeostasis with daily light changes. Photic input is relayed to the brain to entrain the master circadian clock, the suprachiasmatic nucleus, which matches behaviour to environmental changes. Circadian organization of the mouse retina involves coordinated, layer-specific oscillators, but so far little is known about the cone photoreceptor clock and its role in the circadian system. Using the cone-only $\mathrm{Nrl}^{-/-}$mouse model we show that cones contain a functional self-sustained molecular clockwork. By bioluminescence-combined imaging, we also show that cones provide substantial input to the retinal clock network. Furthermore, we found that light entrainment and negative masking in cone-only mice are subtly altered and that constant light displayed profound effects on their central clock. Thus, our study demonstrates the contribution of cones to retinal circadian organisation and their role in finely tuning behaviour to environmental conditions.

Key Words: Nrl, cone, circadian rhythm, phase resetting, retinal clock, negative masking

Abbreviations: Cnga3, Cyclic Nucleotide Gated Channel Subunit Alpha 3; Crx, Cone-Rod Homeobox. 


\section{Declarations}

Funding: this project was supported by funding from Retina France and the University of Strasbourg Institute of Advanced Studies, as well as fellowships from Institut Servier and ISN-CAEN to PW.

Conflicts of interest/Competing interests: the authors declare no competing interests

Availability of data and material: data supporting the conclusions of this article are included within the article and supplementary data

Code availability: not applicable

Authors' contributions: Material preparation, data collection and analysis were performed by Cristina Sandu, Prapimpun Wongchitrat, Nadia Mazzaro, Catherine Jaeger, Hugo Calligaro and Jorge Mendoza. The first draft was written by Cristina Sandu. All authors contributed to the study design, commented on previous versions and approved the final manuscript. David Hicks provided resources. Funding was obtained by Prapimpun Wongchitrat and Marie-Paule Felder-Schmittbuhl.

Ethics approval: All experimental procedures were performed in accordance with the Association for Research in Vision and Ophthalmology Statement on Use of Animals in Ophthalmic and Vision Research, as well as with the European Union Directive (2010/63/EU).

Consent to participate: not applicable

Consent for publication: not applicable 


\section{Introduction}

Adaptation of behaviour and physiology to the $24 \mathrm{~h}$ light/dark (LD) cycle produced by the Earth’s rotation around its axis is one of the main constraints affecting living organisms. Such adaptation is mediated by the circadian system, a network of tissue/cell-specific oscillators with an internal period close to (circa) 24 h, which in mammals is coordinated by a master clock located in the hypothalamic suprachiasmatic nuclei (SCN) (for review: [1]). Daily behavioural and physiological rhythms are controlled by cell autonomous molecular oscillators constituted of oscillating auto-regulatory clock transcription factors able to drive gene expression programs, hence cellular physiology. The retina plays a particular role in the circadian system in mammals because it is responsible for the unique photosensory input to ensure entrainment of the clock in the SCN to the LD cycle [2, 3].

The retina was the first circadian clock identified outside the SCN, based on the capacity of explanted tissue from hamsters to secrete melatonin in a rhythmic manner [4]. Since the retinal clock is able to synchronize to the LD cycle in vitro, this tissue constitutes on its own a complete circadian system, with molecular clock machinery, resetting input mechanism and biological outputs $[5,6]$. Besides melatonin synthesis the retina displays a plethora of rhythmic properties, including expression of photopigment genes, processing of light information, phagocytosis of photoreceptor outer segments, metabolism, together contributing to adapt visual function to the LD cycle and ensuring tissue homeostasis (for review [7]). Given the complexity of the retinal tissue comprising glial cells and six major types of neurons, identification of the cell type(s) constituting its main oscillator has been a matter of debate. Analysis of clock gene expression in vitro and ex vivo suggested that the retina is composed of several layer-specific, coupled oscillators [8-10] but the existence/identity of a main driver remains under question. Several lines of evidence, notably the presence of 
melatonin synthesis machinery [11, 12], the detection of cycling clock factors [13], have pointed to cones as a potential retinal clock component but their precise contribution to the network has not been evaluated.

The retina possesses a laminar organisation as well as parallel microcircuits processing light information. Photon capture occurs in photoreceptors, highly specialized cells located in the outer retina. Cones respond to bright light (photopic vision) and mediate color vision whereas rods are much more sensitive and function under low intensities (scotopic vision). In mice, most cones (95\%) express 2 types of opsins (short wavelength - sws, with maximal sensitivity at $360 \mathrm{~nm}$ and middle wavelength - mws, with peak sensitivity at $509 \mathrm{~nm}$ ) in a dorsoventral gradient with M-opsin and S-opsin dominating in the dorsal and ventral retina respectively [14-16]. A minority of "genuine S-cones" express only S-opsin and are homogeneously distributed over the retina [17]. Investigation of cone properties has been challenging given their low number in retinas of routinely used laboratory mammals, i.e., $<3 \%$ of total photoreceptors in mice [18] and $<1 \%$ in rats [19]. The $\mathrm{Nrl}^{-/-}$mouse [20], in which absence of the NRL transcription factor totally blunts rod generation, has a retina whose photoreceptors are only cones, with a majority of S-cones, and has been extensively used to study cone properties without the interference from rods [13, 21, 22].

Studies from the last 20 years have led to improved understanding of how information linked to light perception in the eye is conveyed to the SCN and translated into a message reflecting the alternation of day and night, able to entrain the central clock. In particular, a minor, lightsensitive population of retinal ganglion cells (RGC) expressing the melanopsin photopigment (intrinsically photosensitive RGC or ipRGC) constitutes the (unique) cellular connection between the retina and the SCN [23-25]. Despite the major role played by these blue light sensors (peak sensitivity $=480 \mathrm{~nm}$ ), some data demonstrate a role for rods in synchronisation 
to the LD cycle at low light intensities [26-28] and also for cones [29-31]. In addition, recent results in mice suggested that cones also play a role in entrainment mechanisms by perceiving spectral changes characteristic of dusk or dawn [32, 33]. However, these functions have not been investigated with gain of function mutants, in particular for cones.

Here we investigate the role of murine cones in the circadian system. We show that cones in the $\mathrm{Nrl}^{-/}$retina harbor a functional molecular clock, the elements of which are similar to other central or peripheral clocks. Furthermore, the cone population contributes, together with the inner and ganglion cell layers, to the oscillatory network of the retina. However, lightmediated behavior seems to be altered in the cone-only retina from $\mathrm{Nrl}$ mutant mice in acute and chronic light exposure conditions, particularly at low light intensities. This suggests that total replacement of rods by cones induces modifications in the global non-image forming visual function of the retina in mice. 


\section{Materials and methods}

\section{Animals}

Mice were handled according to the French Law implementing the European Union Directive 2010/63/EU. All procedures involving the use of mice were approved by the Animal Use and Care Committee from Strasbourg (CREMEAS). $\mathrm{Nr}^{-/-}$(C57Bl/6J background) mice were obtained from Dr. C. Grimm (Laboratory of Retinal Cell biology, University Hospital Zurich, Switzerland) with permission from Dr. A. Swaroop (NEI, Bethesda, MD, USA) [20]. mPer2 ${ }^{\text {Luc }}$ mice [34] (C57Bl/6J background, previously purchased from The Jackson Laboratory, Bar Harbor, ME, USA) were crossed with $\mathrm{Nrl}$ mutants to generate the $\mathrm{Nrl}^{-/-}$ Per2 ${ }^{\text {Luc }}$ and $\mathrm{Nrl}^{+/+}$Per2 ${ }^{\text {Luc }}$ animals. According to experiments, WT $\left(\mathrm{Nrl}^{+/+}\right)$and $\mathrm{KO}\left(\mathrm{Nrl}^{-/-}\right)$ animals were either homozygous for the Per2 $2^{\text {Luc }}$ knock-in allele (stated Per2 ${ }^{\text {Luc }}$ background) or did not contain Per2 ${ }^{\text {Luc }}$ allele. All the mice were raised in the Chronobiotron animal facility (UMS 3415, Strasbourg, France) and housed in standard cages in groups of 3 to 4 individuals, under 12h:12h light-dark (LD) cycles [ZT0-light on, ZT12-light off; broad spectrum (400-650 nm) white light at 300 lux (MASTER PL-L 4 lamp, Philips, France); no red light at night] with food and water ad libitum and in an ambient temperature of $22 \pm 1^{\circ} \mathrm{C}$. Experiments were performed on both males and females unless otherwise stated. In most cases, no a priori estimation of sample size was performed. Our groups were based on previous or preliminary data and tried to conform to the 3R rule.

\section{Laser microdissection}

Six week-old $\mathrm{Nr}^{-/-}$males $(\mathrm{n}=30)$ reared in LD were exposed to constant dark (dark/dark, DD; no dim red light). After $36 \mathrm{~h}$ in DD mice were euthanized within the following $24 \mathrm{~h}$ in DD in a $\mathrm{CO}_{2}$ (up to 20\%) airtight chamber at the following projected ZT time points: 0,4 , 8, 12, 16, 20 ( $n=5$, randomly allocated, per time point). Eyes were enucleated, embedded in 
Tissue-Tek OCT compound (Sakura Finetek USA, Torrance, CA), frozen on dry ice and stored at $-80^{\circ} \mathrm{C}$ until use. Animal handling and eye sampling were performed by using night vision goggles (ATN NVG-7, ATN-Optics, Chorges, France).

$20 \mu \mathrm{m}$ thick eyeball sections were cut on cryostat and placed on polyethylene naphthalate (PEN) Membrane Frame slides (Life Technologies, Grand Island, NY). Three to four slides (4 sections/slide) were prepared from a single eye specimen. Each slide was stored at $-80^{\circ} \mathrm{C}$ in a $50 \mathrm{~mL}$ nuclease-free tube (pre-chilled on dry ice) and used for laser microdissection within a week.

Frozen slides were thawed at room temperature for 30 s. Sections were stained with cresyl violet (1\% cresyl violet acetate in $70 \%$ ethanol) for $30 \mathrm{~s}$, then dehydrated through a series of ethanol solutions: 2 x $75 \%$ for 30 s, $95 \%$ for 30 s, $100 \%$ for 30 s and $100 \%$ for 2 min. Slides were air dried at room temperature for 1 min then completely dehydrated in a vacuum chamber for $1 \mathrm{~h}$ before microdissection. The whole procedure was performed in RNase free conditions.

Laser microdissection was performed using the Veritas Microdissection Arcturus system and software (Arcturus Bioscience, Inc. Mountain View, CA, USA) immediately after complete dehydration of the slides. The cone photoreceptor areas of interest were selected under microscope (20x magnification) and transferred on CapSure Macro LCM Caps (Life Technologies, Grand Island, NY) by the combined use of the infrared (power 70-80 mW, pulse 1500-3500 $\mu \mathrm{s}$ ) and UV (low power 2-4) lasers (See also Figure 1A). A total cone photoreceptor area of $3 \mathrm{~mm}^{2}$ was collected per eye. In order to prevent RNase reactivation and RNA degradation, the microdissection was carried out within maximum 60 min for each slide. 3-4 caps/eye were collected into the same reaction tube which contained $\mathrm{RLT}^{+}$lysis buffer (Qiagen, Hilden, Germany) and stored at $-80^{\circ} \mathrm{C}$. 


\section{Quantitative reverse-transcription PCR}

Total RNA was extracted from the microdissection lysates using RNeasy Plus Micro kit (Qiagen, Hilden, Germany) according to the manufacturer's instructions and eluted in a final volume of $12 \mu \mathrm{L}$. RNA quantity and purity were measured using the Nanodrop ND-1000 spectrophotometer (Thermo Scientific, Wilmington, DE, USA). RNA integrity was assessed with the 2100 Bioanalyzer (Agilent Technologies, Santa Clara, CA, USA) and the RNA 6000 Pico chips (Agilent Technologies, Santa Clara, CA, USA), following the manufacturer's instructions. 25 ng of RNA from samples with the RNA integrity number (RIN) $>6(n=3-5)$ were amplified using ExpressArt mRNA amplification Nano kit (Amsbio, Oxon, UK). 150 ng of amplified RNA was reverse transcribed by using the iScript ${ }^{\mathrm{TM}}$ Advanced cDNA Synthesis Kit for RT-qPCR (Bio-Rad, Hercules, CA, USA) in a final volume of $20 \mu \mathrm{L}$. All samples were stored at $-80^{\circ} \mathrm{C}$.

Transcript levels were determined by quantitative PCR as described [10], with PCR reactions run in duplicates. The purity of the microdissected samples was verified by the absence of detection by qPCR, of transcripts for tyrosine hydroxylase (Th) gene and metabotropic glutamate receptor 6 (mGluR6) gene, as markers for the inner nuclear layer. Transcript levels were normalized to the levels of Tbp and Hprt which showed constant expression in the isolated cones over the $24 \mathrm{~h}$ (data not shown). All TaqMan probe-based assays were purchased from Applied Biosystems (Applied Biosystems, Foster City, CA, USA) and designed to span exon boundaries (Supplementary Table 1). Data was quantified using the $\Delta \mathrm{Cq}$ method, modified to take into account gene-specific amplification efficiencies and multiple reference genes, and the qBase software (free v1.3.5) [35]. In microdissected cones, log transcript levels were calculated relative to the transcript levels measured in a WT photoreceptor sample which were rescaled to one. We used Excell software to detect outliers 
which were removed for the final statistical analysis $(n=1$ for Per1, Per2 and Per3 quantification).

\section{Real-time bioluminescence recordings}

Bioluminescence recordings from whole retinas and isolated photoreceptor layers were obtained in several successive experiments and data were analysed all together. Only samples generating a bioluminescence signal above the background level (similar level for both genotypes: $80 \%$ samples for whole retina and $30 \%$ samples for photoreceptor layers) were retained in the study.

\section{Whole retina explant cultures}

WT and KO mice (5-6 week-old, Per2 ${ }^{\text {Luc }}$ background), were euthanized with $\mathrm{CO}_{2}$ (progressive increase up to $20 \%$ in an airtight box) during the light phase and enucleated. Eyeballs were kept at room temperature in HBSS 11 x HBSS (Sigma-Aldrich, Steinheim, Germany) containing antibiotics (100 U/mL penicillin and $100 \mathrm{mg} / \mathrm{ml}$ streptomycin, SigmaAldrich, Steinheim, Germany), 100 mM HEPES (Sigma-Aldrich, Steinheim, Germany) and $4.2 \mathrm{mM}$ sodium bicarbonate (Sigma-Aldrich, Steinheim, Germany)] for whole retina dissection. The eye ball was incised under the ora serrata and the cornea and lens were cut out. Retinas were carefully detached from the retinal pigment epithelium and flattened with small radial incisions.

Each flattened retina was placed, photoreceptors down, onto a semipermeable membrane (Millipore, Billerica, MA, USA) in a $35 \mathrm{~mm}$ culture dish (Nunc, ThermoFisher, France) containing pre-incubation medium [1 ml neurobasal A medium (Gibco, Invitrogen, Life Technologies, Carlsbad, CA, USA) supplemented with antibiotics (25 U/ml penicillin and 25 mg/mL streptomycin, Sigma-Aldrich), 2\% B27 (Invitrogen, Life Technologies, Grand Island, NY, USA), and 2 mM L-glutamine (Gibco, Life Technologies, Carlsbad, CA, USA). Samples 
were kept $24 \mathrm{~h}$ at $37^{\circ} \mathrm{C}$ in a humidified $5 \% \mathrm{CO}_{2}$ incubator then the medium was changed with pre-warmed $\left(37^{\circ} \mathrm{C}\right) 199$ recording medium [1 mL medium 199 (Sigma-Aldrich, St. Louis, MO, USA) supplemented with antibiotics (25 U/mL penicillin and $25 \mathrm{mg} / \mathrm{mL}$ streptomycin, Sigma-Aldrich), 4 mM sodium bicarbonate, 20 mM D(+)-glucose (Sigma-Aldrich), 2\% B27 (Invitrogen), 0.7 mM L-glutamine (Gibco), and 100 mM beetle luciferin (Promega, Fitchburg, WI, USA)]. The medium change was performed under dim red light. Dishes were sealed with high-vacuum grease (Dow Corning; Midland, MI, USA) and placed into the LumiCycle (Actimetrix, Wilmette, IL, USA) heated at $36^{\circ} \mathrm{C}$. Samples were recorded during 6-8 days and the photons were integrated for 112 s every $15 \mathrm{~min}$. In bioluminescence recordings, the 2 retinas from the same animal are considered as independent, biological replicates. We here analysed $\mathrm{n}=12$ (8 mice) for WT and $\mathrm{n}=12$ (7 mice) for KO.

\section{Photoreceptor layer explant cultures}

Retinas were dissected as described above. Photoreceptor layers were isolated using the vibratome technique and cultured as reported previously [9]. WT ( $\mathrm{n}=6$ samples, 6 mice) and KO ( $\mathrm{n}=9$ samples, 8 mice) photoreceptor explants were recorded for at least 5 days and the photons were integrated for 112 s every 15 min. Exceptionally, when layers of insufficient size were collected, samples from both retinas were cultured together (2 samples in WT group, 1 sample in KO group).

\section{Transversal retinal slice imaging}

Flattened retinas (4 week-old KO mice, $\mathrm{n}=3$, Per $2^{\text {Luc }}$ background) were mounted with warm $\left(37^{\circ} \mathrm{C}\right) 5 \%$ gelatin on top of a $10 \%$ gelatin block. The whole retina-embedded block was glued on the tissue holder and then placed into the tissue bath (containing HBSS, SigmaAldrich) of a Vibroslice MA752 (Campden Instruments, Loughborough, England). A 
transversal $100 \mu \mathrm{m}$ thick slice was cut, placed carefully on a semipermeable membrane in a $35 \mathrm{~mm}$ culture dish and pre-incubated with Neurobasal A medium for $24 \mathrm{~h}$. Just before imaging the medium was replaced with pre-warmed recording medium under dim red light. The sealed dish was placed into the culture chamber $\left(37^{\circ} \mathrm{C}\right)$ of a Luminoview 200 microscope (Olympus, Hamburg, Germany) equipped with an EM-CCD camera (Hamamatsu, Japan) cooled to $-76^{\circ} \mathrm{C}$. Bioluminescence images (20x objective, EM gain $=80,1 \times 1$ binning of pixels) were taken every 2 h over minimum 3 days.

\section{SCN bioluminescence recordings}

Animals (9 month-old, WT $\mathrm{n}=5, \mathrm{KO} \mathrm{n}=7$, Per2 $^{\text {Luc }}$ background) were killed by cervical

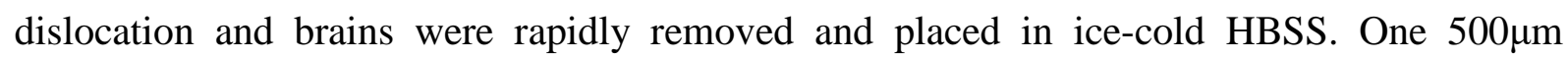
coronal section of the SCN region was obtained using a stainless steel adult mouse brain slicer matrix (ZIVIC Instruments, Pittsburgh, USA), then trimmed to $1 \times 1 \mathrm{~mm}$. Each SCN explant (containing both nuclei) was cultured onto a Millicell culture membrane (Merck Millipore Ltd, Tullagreen, Ireland) in a 35-mm culture dish with $1 \mathrm{~mL}$ of DMEM (Sigma-Aldrich) supplemented with $0.35 \% \mathrm{D}(+)$-glucose, $0.035 \%$ sodium bicarbonate, $10 \mathrm{mM}$ HEPES, 2\% B27, antibiotics (25U/mL penicillin and 25mg/mL streptomycin) and $0.1 \mathrm{mM}$ beetle luciferin. Culture dishes were sealed with vacuum grease. The bioluminescence was recorded using the LumiCycle for $112 \mathrm{~s}$ in 15 min intervals and during at least 6 days.

\section{Bioluminescence data analysis}

Whole retina and SCN explant PER2::LUC raw data were subtracted with a 24 h running average (removal of the baseline drift) using the LumiCycle analysis software (Actimetrics, Wilmette, IL, USA). The first cycle was removed and the analysis was performed on the following 4 (retina) or 5 (SCN) cycles. The robustness of the rhythms (relative rhythmic power [36]) and the phase were also calculated using the LumiCycle analysis software. The 
period, amplitude and damping rate were determined using a cosinor derived sine wave function: $\mathrm{f}=\mathrm{y} 0+\mathrm{a} * \exp (-\mathrm{x} / \mathrm{d}) * \sin [2 * \pi *(\mathrm{x}+\mathrm{c}) / \mathrm{b}]$ where a is the amplitude (counts/s), $\mathrm{b}$ is the period (h), c is the phase-related term (h) and $\mathrm{d}$ is the damping rate (days) and assuming that damping follows an exponential pattern. Baseline for each individual peak in retinal samples was estimated as the baseline from LumiCycle analysis taken at the peak time. Photoreceptor layer data were analyzed as previously described, on 4 successive cycles [9].

Bioluminescence data from whole retinas and photoreceptor layers were obtained over several series of recordings: samples for which activity did not exceed the background of Lumicycle were excluded from the study.

Transversal retinal images were analyzed with ImageJ (open source software https://imagej.nih.gov/). A median 3D filter was applied to remove the hotspots. The ganglion cell layer (GCL), inner nuclear layer (INL) and photoreceptor layer (PRL) were defined as regions of interest (ROI) and the bioluminescence levels (grey levels) were measured and exported for the analysis of rhythmicity. The periods were determined using the cosinor derived sine wave function: $\mathrm{f}=\mathrm{y} 0+\mathrm{a} * \exp (-\mathrm{x} / \mathrm{d}) * \sin [2 * \pi *(\mathrm{x}+\mathrm{c}) / \mathrm{b}]$ as above.

\section{Locomotor activity recordings}

For behavioural recordings, male and female mice (WT and KO combined or not with the Per2 ${ }^{\text {Luc }}$ knock-in allele) were housed in individual standard cages equipped with a $10-\mathrm{cm}$ diameter stainless steel running wheel [37] or with infrared detectors placed above the cage and linked to an automated recording system (CAMS, Circadian Activity Monitoring System, Lyon, France) as previously described [38]. Data were collected in 5 min bins and analysed with the ClockLab Software (Actimetrics, Wilmette, IL, USA). Locomotor activity data were represented as double-plotted in actograms. 


\section{Circadian phenotype}

To determine the daily and circadian rhythm of locomotor activity in $\mathrm{Nrl}$ mutant mice, 5-6 month-old mice (WT $\mathrm{n}=4, \mathrm{KO} n=7$, Per2 $^{\text {Luc }}$ background) were initially maintained for 10 days under LD 12:12 and then 16 days under constant darkness (DD). Total activity and rhoand alpha-phase activity levels were calculated over the last 3 days in LD and the endogenous period (Chi-square Periodogram method) was determined over 10-day interval after 7 days from the transition to DD.

\section{Behavioural phase-shifts to light pulses}

To evaluate phase shifting in response to light pulses 5-6 week-old mice $(\mathrm{WT} \mathrm{n}=5, \mathrm{KO} n=$ 8) were initially maintained in LD 12:12 (100 lux) and then challenged by 3 alternating DD (9-14 days) - LD (14-18 days) cycles. On the day before each light-pulse, the room lights went off at ZT12. On the following day a 15 min light pulse (LP) was applied at the projected ZT15. Then lights remained off for at least 9 days before re-exposing animals to LD condition. The intensity of the light pulses decreased one order of magnitude as indicated in Figure 3A, B. To determine phase changes in control and $\mathrm{Nrl}$ mutant mice, a linear regression analysis of the activity onsets was performed by projecting the onset phase of the free run in DD back to the mean onset phase under LD condition (ClockLab).

\section{Masking}

To evaluate the negative masking response to light, 3-6 month-old mice (WT $n=6, \mathrm{KO} n=7$, Per2 ${ }^{\text {Luc }}$ background) mice adapted to $12: 12$ LD cycle were housed in individual cages into a ventilated cabinet (Charles River Laboratories, France) equipped with broad spectrum white light lamp (MASTER TL-D Super 80 lamp, Philips). The masking effect of light was tested by exposing the animals to light for 3 hours from ZT14 to ZT17 at successive light intensities as follows: day 1 (baseline) - standard 12:12 LD; day 2 - ZT14-17 at <1 lux; day 4 - ZT14-17 
at 1-10 lux; day 6 - ZT14-17 at 10-50 lux; day 8 - ZT14-17 at 200-400 lux; days 3, 5, 7 standard 12:12 LD. Locomotor activity was monitored with infrared cage top motion sensors connected to the CAMS data acquisition system (Circadian Activity Monitoring system, INSERM, Lyon, France) [29]. The percent of activity during the $3 \mathrm{~h}$ light pulse was calculated relative to the $12 \mathrm{~h}$ activity of the preceding standard night.

\section{Re-entrainment to 6-h light-dark cycle delay}

1.5-3 month-old mice (WT $\mathrm{n}=5, \mathrm{KO} \mathrm{n}=5$ ) were kept for 23 days in LD at 100 lux (LD1) and then challenged with 4 successive 6-h phase delays, mimicking a jet-lag (JL) or cycle change across six time zones, combined with reduction of light intensity: JL1 (21 days, 100 lux), JL2 (22 days, 10 lux), JL3 (51 days, 1 lux) JL4 (50 days, 0,1 lux). At the end of the last JL exposure, animals were transferred to DD (22 days) and then re-exposed 25 days to LD at 100 lux (LD2). The phase angle of entrainment was determined by calculating the difference between the time of lights off and the time of activity onset (ClockLab).

\section{Exposure to constant light}

Effects of constant light exposure (light/light, LL) were assessed by wheel running activity in 6 month-old mice (WT $\mathrm{n}=6, \mathrm{KO} \mathrm{n}=7, \mathrm{Per}^{\mathrm{Luc}}$ background). Thus, after 10 days in LD 12:12 animals were transferred to LL for 70 days (130 \pm 34 lux on average). Total activity per cycle, period and relative rhythmic power were measured by using ClockLab. Mice were then exposed to a second LD cycle (LD2: 10 days) to evaluate if entrainment and locomotor activity returned to baseline levels.

\section{Statistical analysis}

Results are expressed as means \pm SEM, except for qPCR data. Statistical analyses were performed by using SigmaPlot 12 software (Systat Software, San Jose, CA, USA). Comparison of two groups was performed by using the Student's t test. Comparison of several 
groups was performed by using 1-way or 2-way ANOVA for independent and repeated measures, followed by post hoc test (Holm-Sidak test).

Data from qRT-PCR over $24 \mathrm{~h}$ in DD were also analyzed by nonlinear least-square fitting of a 24 h sinusoid (cosinor analysis) $\mathrm{f}=\mathrm{a}+[\mathrm{b} * \cos (2 * \pi *(\mathrm{x}-\mathrm{c}) / 24)]$ [39]. A posteriori Power analysis was also performed (Supplementary Table 2).

A statistically significant difference was assumed with $p$ values less than 0.05 . 


\section{Results}

\section{A functional clock in cone photoreceptors}

We first aimed to characterize the cone molecular clock on microdissected photoreceptors isolated from the $\mathrm{Nrl} \mathrm{KO}$ mice over $24 \mathrm{~h}$ in DD (Figure 1A). We found that all core clock gene transcripts examined, Bmal1, Clock, Per1, Per2, Per3, Cry1, Cry2, Rev-Erb $\alpha$, Ror $\beta$ are expressed in cones (Figure 1B, top panel). Significant rhythmic levels of expression were determined for Bmal1, Per1, Per2, Per3, Rev-Erba (Table 1 and Supplementary table 2). Interestingly, the expression profile of Bmal1 was in opposite phase in comparison to the profiles of Per transcripts, as described in the SCN [40, 41] and other peripheral tissues such as liver [42, 43]. $24 \mathrm{~h}$ profiles in cones were also similar, at least for Bmal1 and Per1 transcripts, to those reported for mouse whole retinas sampled in DD [44].

We also investigated the expression of several well-known or putative target genes of the retinal clock such as S-opsin, M-opsin, Crx, arrestin 3, Cnga3 and c-Fos transcripts (Figure1 B, lower panel). S-opsin, arrestin 3 and Cnga3, expressed in S-cones [20], displayed significantly rhythmic profiles (Table 1 and Supplementary table 2).

To further evaluate the capacity of cones to sustain rhythmicity, we used a vibratome-based sectioning of the retina to isolate photoreceptor (cone-only) layers from the KO mice raised on the Per2 ${ }^{\text {Luc }}$ reporter background [34] for real-time bioluminescence recordings. Photoreceptor layers from WT mice were used as controls. As previously described [9] the latter showed robust PER2::LUC oscillations with a $26.46 \pm 0.02 \mathrm{~h}$ period (Figure 1C). Cone layers from the $\mathrm{KO}$ retinas also proved robustly rhythmic in culture, but yet with a significantly longer period: $29.07 \pm 0.03 \mathrm{~h}(\mathrm{n}=6$ for $\mathrm{WT}, \mathrm{n}=9$ for KO; genotype effect: $p=$ 0.018) (Figure 1C). 
Finally, we examined how cone layers oscillate within the context of the whole retina by using in vitro real-time bioluminescence combined with imaging. $100 \mu \mathrm{m}$ transversal sections were cut using the vibratome technique illustrated in Figure $1 \mathrm{D}$, transferred on a semipermeable membrane, then cultured and imaged for several days in a temperature controlled microscope chamber. PER2 bioluminescence signal emerged from all layers, with higher intensity in ganglion and inner cell layers and weaker signal in the outer, photoreceptor layer (Figure 1E). Moreover, the PER2 signal was rhythmic in all layers (Figure 1F), with distinct free-run periods $(24.28 \pm 0.26 \mathrm{~h}$ for ganglion cell layers, $27.79 \pm 0.20 \mathrm{~h}$ for inner nuclear layers and $26.80 \pm 1.19$ h for photoreceptor layers; Figure $1 G$ ) (significant layer effect, $p=0.037$ ). Taken together, these data confirm the presence of an autonomous clock in cones. 

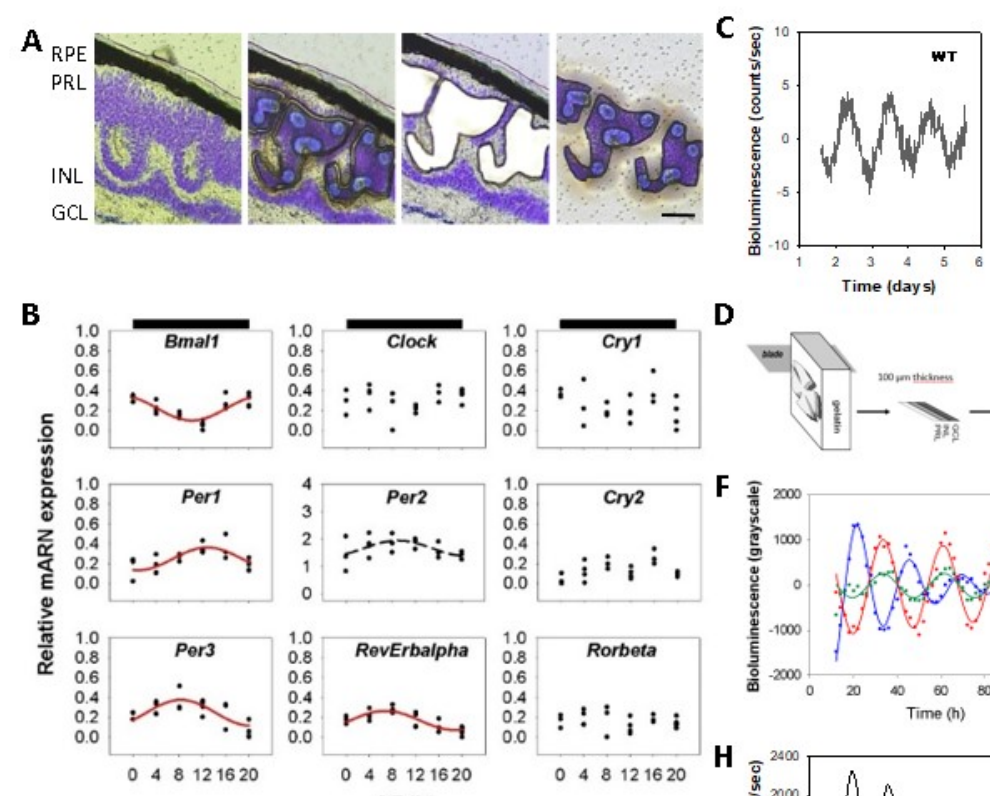
CT (h)
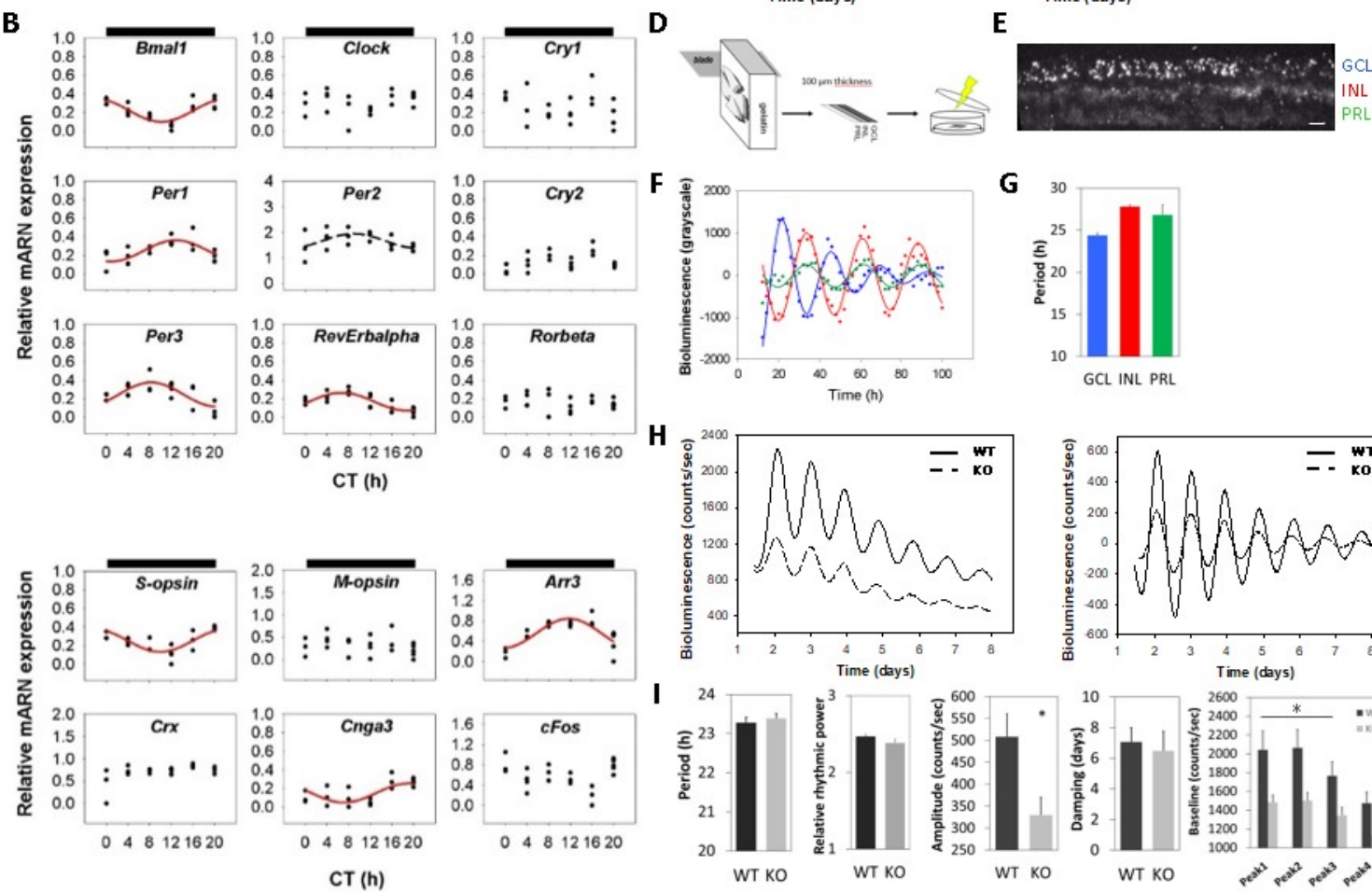

G

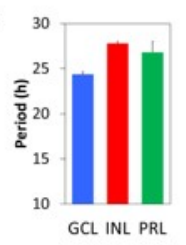

H
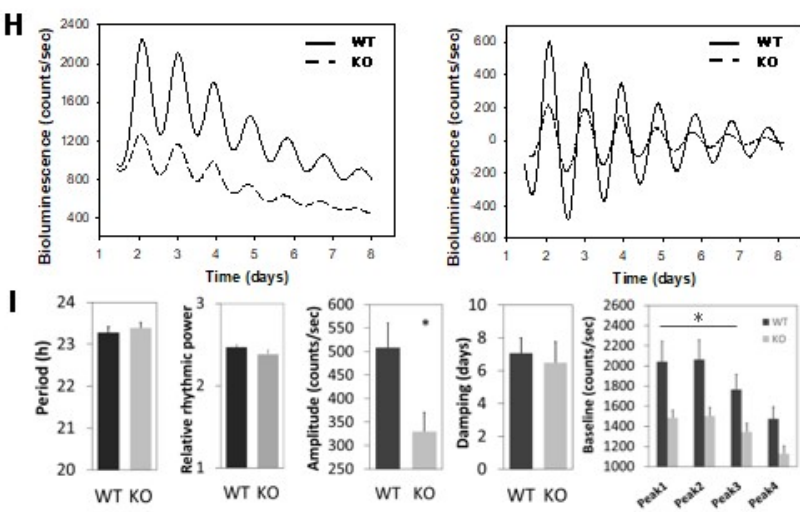

Figure 1: Circadian rhythms in cones and cone-only retinas

(A-C) A functional clock in cone photoreceptors. (A) Cone photoreceptors were microdissected from retinas of $\mathrm{Nrl}^{-/-}$mice sampled throughout $24 \mathrm{~h}$ in constant dark. The successive pictures show, from left to right: the characteristic structure of a cresyl-violet stained retinal section from these 1.5 month $\mathrm{Nrl}^{-/-}$mice with numerous rosettes; the capture/sectioning strategy; the same section after laser cut; the resulting captured sample. The distinct retinal layers (GCL, ganglion cell layer; INL, inner nuclear layer; PRL, photoreceptor layer) and the retinal pigmented epithelium (RPE) are indicated (scale bar $=50$ $\mu \mathrm{m}$ ). (B) Circadian expression profiles of clock genes (top) and clock output genes (bottom) in microdissected cone layers sampled every $4 \mathrm{~h}$ in DD (CT = Circadian Time, corresponding to projected ZT). Expression was analysed by qRT-PCR (data for each sample are presented as relative expression level with respect to a WT photoreceptor calibrator: $n=3-5$ per time point). Traces represent the best-fitted sinusoidal regressions supporting rhythmic gene expression in the cases where both cosinor analysis and ANOVA yielded significant $p$ values. Dashed lines when only cosinor proved significant. Results from statistical analyses are shown in Table 1 and Supplementary Table 2. (C) PER2::LUC rhythms in explanted cone 
layers. Graphs show representative (baseline-subtracted) bioluminescence recordings of photoreceptor layers isolated by vibratome sectioning from WT (left) and KO (right) mice. Periods of oscillations proved significantly longer in mutants $(\mathrm{n}=6$ for WT, $\mathrm{n}=9$ for KO; $\mathrm{t}$ test, $p=0.018$ ). (D-G) Bioluminescence imaging of retinal transversal section from $\mathrm{Nrl}^{-/-}$mice reveals sustained oscillation capacity in cones. (D) Schematic presentation of the vibratomebased strategy for isolating a transversal $100 \mu \mathrm{m}$ thick section from a freshly dissected retina. (E) Representative picture showing bioluminescence emission in the 3 neuronal layers from a $\mathrm{Nrl}^{-/}$section (exposure time $=2 \mathrm{~h}$, scale bar $\left.=100 \mu \mathrm{m}\right)$. (F) Representative bioluminescence counts from the 3 neuronal layers taken individually in one $\mathrm{Nrl}^{-/-}$sample. Damped sinusoids represent the best-fit to subtracted data. (G) Periods were calculated separately for each cell layer and show a significant layer effect $(n=3, p=0.037)$. (H,I) Circadian rhythms are altered in the cone-only retina. $(\mathrm{H})$ Representative raw (left) and baseline-subtracted (right) bioluminescence recordings from WT (solid line) and KO (dashed line) whole retinas showing reduced baseline and amplitude of the mutant retinas. (I) Period, relative rhythmic power, amplitude, damping and baseline levels were compared between WT and mutant retinas and revealed a significant difference in amplitude (t-test, $p=0.013$ ) and baseline levels (repeated measures 2-way ANOVA, $p=0.015$ ) between genotypes ( $\mathrm{n}=12$ per genotype). Results are represented as mean \pm SEM. *: $p<0.05$. 


\begin{tabular}{|c|c|c|c|c|c|c|c|c|c|c|}
\hline Gene & $p_{\text {cosinor }}$ & $F_{\text {cosinor }}$ & $\mathbf{a}$ & $p_{\mathbf{a}}$ & $\mathbf{b}$ & $p_{\mathbf{b}}$ & C & $p_{c}$ & $p_{\text {ANOVA }}$ & $\boldsymbol{F}_{\text {ANOVA }}$ \\
\hline Bmal1 & $<0.0001$ & $F(2,19)=19.29$ & 0.221 & $<0.0001$ & 0.123 & $<0.0001$ & 22.13 & $<0.0001$ & $<0.001$ & $F(5,21)=12.89$ \\
\hline Clock & 0.1851 & $F(2,19)=1.84$ & 0.303 & $<0.0001$ & 0.062 & 0.07 & 21.58 & $<0.0001$ & 0.21 & $F(5,21)=1.63$ \\
\hline Cry1 & 0.9489 & $F(2,19)=0.05$ & 0.248 & $<0.0001$ & 0.015 & 0.74 & 21.82 & 0.0866 & 0.12 & $F(5,21)=2.08$ \\
\hline Cry2 & 0.1435 & $F(2,19)=2.15$ & 0.132 & $<0.0001$ & 0.054 & 0.05 & 12.38 & $<0.0001$ & 0.006 & $\mathrm{~F}(5,21)=5.09$ \\
\hline Per1* & 0.0014 & $F(2,19)=9.75$ & 0.245 & $<0.0001$ & 0.115 & 0.0003 & 12.81 & $<0.0001$ & 0.02 & $F(5,20)=12.90$ \\
\hline Per2* & 0.0326 & $F(2,19)=4.17$ & 1.653 & $<0.0001$ & 0.286 & 0.0098 & 8.99 & $<0.0001$ & 0.22 & Eqvar failed \\
\hline Per3* & 0.001 & $F(2,19)=10.41$ & 0.245 & $<0.0001$ & 0.13 & 0.0002 & 8.25 & $<0.0001$ & 0.007 & $F(5,20)=4.94$ \\
\hline$R e v-E r b \alpha$ & $<0.0001$ & $F(2,19)=17.56$ & 0.168 & $<0.0001$ & 0.096 & $<0.0001$ & 6.72 & $<0.0001$ & 0.001 & $F(5,21)=7.22$ \\
\hline $\operatorname{Ror} \beta$ & 0.6356 & $F(2,19)=0.46$ & 0.161 & $<0.0001$ & 0.023 & 0.34 & 2.94 & 0.45 & 0.71 & $F(5,21)=0.585$ \\
\hline
\end{tabular}

\begin{tabular}{|c|c|c|c|c|c|c|c|c|c|c|}
\hline M-opsin & 0.6325 & $\mathrm{~F}(2,19)=0.47$ & 0.324 & $<0.0001$ & 0.06 & 0.34 & 7.09 & 0.09 & 0.49 & $\mathrm{~F}(5,21)=0.489$ \\
\hline S-opsin & $<0.0001$ & $\mathrm{~F}(2,19)=16.47$ & 0.252 & $<0.0001$ & 0.12 & $<0.001$ & 21.94 & $<0.0001$ & $<0.0001$ & $\mathrm{~F}(5,21)=9.08$ \\
\hline Arrestin 3 & $<0.0001$ & $\mathrm{~F}(2,19)=17.89$ & 0.56 & $<0.0001$ & 0.288 & $<0.0001$ & 11.7 & $<0.0001$ & 0.004 & Norm failed \\
\hline Cnga3 & 0.003 & $\mathrm{~F}(2,19)=8.04$ & 0.15 & $<0.0001$ & 0.103 & 0.0008 & 19.1 & $<0.0001$ & 0.001 & $\mathrm{~F}(5,21)=7.168$ \\
\hline Crx & 0.1929 & $\mathrm{~F}(2,19)=1.80$ & 0.698 & $<0.0001$ & 0.099 & 0.07 & 13.35 & $<0.0001$ & 0.11 & Norm failed \\
\hline c-Fos & 0.0809 & $\mathrm{~F}(2,19)=2.88$ & 0.581 & $<0.0001$ & 0.169 & 0.03 & 0.06 & 0.9689 & 0.002 & $\mathrm{~F}(5,21)=6.635$ \\
\hline
\end{tabular}

Table 1: Cosinor analysis and ANOVA for gene expression results

(a, mesor; b, amplitude; c, acrophase)

* One outlier sample was removed from analysis 


\section{Clock properties in a cone-only retina}

We then examined how the unique presence of cones affects the overall circadian function in the mouse retina. Previous bioluminescence studies demonstrated that mouse retina displays oscillatory expression of PER2 [9, 44]. To evaluate how a cone-only photoreceptor population impacts on the retinal clock we performed real-time bioluminescence recordings of whole retinal explants from $\mathrm{Nrl}^{-/}$Per2 ${ }^{\mathrm{Luc}}$ mice, compared to WT controls (Figure 1H). Sustained circadian oscillations of PER2 bioluminescence were observed for several days, with no difference in period ( $p=0.557)$, relative rhythmic power $(p=0.273)$ and damping $(p=0.583)$ comparing to the wild-type littermates (Figure 1I). However, the amplitude of the oscillations was significantly reduced in the mutants by 35\% $(p=0.013)$. Moreover, a significant reduction of the baseline levels was observed in mutant mice as compared to wild-type ( $p=$ 0.015) (Figure 1H and 1I).

To make sure the observed effects were not induced by alterations of other cell types known to play a role in the retinal clock network, we evaluated whether the $\mathrm{Nrl}^{-/-}$mutation affected two retinal cell populations; the intrinsically photosensitive ganglion cells (ipRGC) which express melanopsin (OPN4) photopigment and the dopaminergic amacrine cells which express tyrosine hydroxylase (TH). Both total numbers of cells analyzed by immunostaining ( $p=0.433$ and $p=0.176$, for OPN4 and TH respectively; Supplementary Figure 1A,B) and mRNA levels quantified by real-time qRT-PCR of whole retinas $(p=0.426$ and $p=0.156$, respectively; Supplementary Figure 1C) showed no significant differences between wild-type and mutant retinas. By contrast, we observed a 2-fold increase in the level of expression of Opn1mw in the $\mathrm{Nrl}$ mutants $(p<0.0001)$, as previously described [20, 45]. Despite normal number and phenotype of dopaminergic cells, KO retinas displayed altered dopamine metabolism in response to light (Supplementary Figure 1D), as known for rodless retinas [46]. 
Thus, the changes related to rhythms measured in vitro in the $\mathrm{Nr}^{-/-}$retinas are likely to result mainly from their specific photoreceptor composition.

\section{SCN-driven rhythms are preserved in the cone-only mouse}

SCN explants from $\mathrm{Nr}^{-/}$Per2 ${ }^{\text {Luc }}$ mice produced autonomous and sustained PER2::LUC oscillations for at least 6 days in vitro similar to those from WT (Figure 2A). The robustness of rhythms was similar between genotypes, based on the relative rhythmic power ( $p=0.344$ ), indicating that in the cone-only mutant the master clock is not impaired (Figure 2B). Moreover, there was no effect on the phase of the oscillations $(p=0.938)$ and on the amplitude $(p=0.476)$, period $(p=0.944)$ and damping $(p=0.09)$ (Figure $2 \mathrm{C}-\mathrm{F})$. Thus, the SCN clock is not affected by the absence of rods in the standard conditions in which it was evaluated here.

We also recorded wheel-running activity of the $\mathrm{Nr}^{-/-} \mathrm{Per} 2^{\mathrm{Luc}}$ mice in order to determine their circadian phenotype. These behavioral studies were conducted under classical white spectrum light, to which KO mice respond similarly to WT (Supplementary Figure 2). Activity profiles (Figure 2G and Supplementary Figure 3) showed no significant differences between $\mathrm{Nrl}$ mutants and their wild-type littermates, in LD 12:12, regarding the amount of total activity (14359 \pm 3837 counts/24 h vs $17691 \pm 3753$ counts/24 h in WT and KO mice respectively; $p$ $=0.579)$, the rho-phase activity (219 \pm 131 counts/24 h vs $241 \pm 73$ counts/24 h; $p=0.877)$ and alpha-phase activity (14140 \pm 3959 counts/24 h vs $17450 \pm 3780$ counts/24 h; $p=0.586)$ levels (Figure 2H). The endogenous period was measured under free-run conditions in DD and showed similar values between WT $(23.96 \pm 0.10 \mathrm{~h})$ and $\mathrm{KO}(23.85 \pm 0.05 \mathrm{~h})(p=0.278)$ (Figure 2I). 


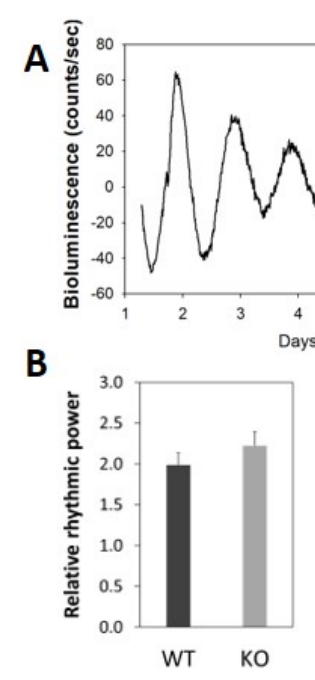

D

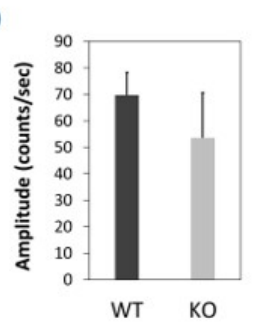

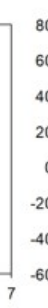

C
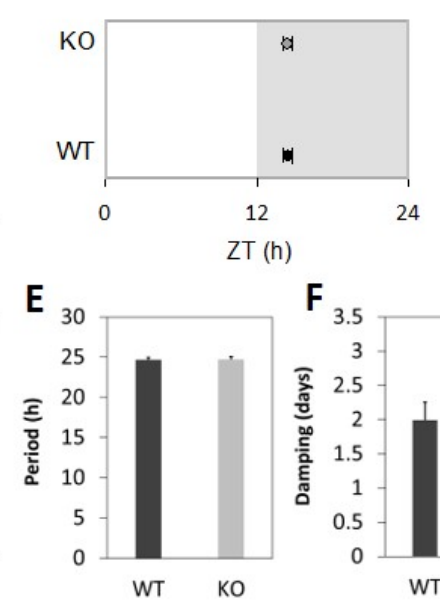
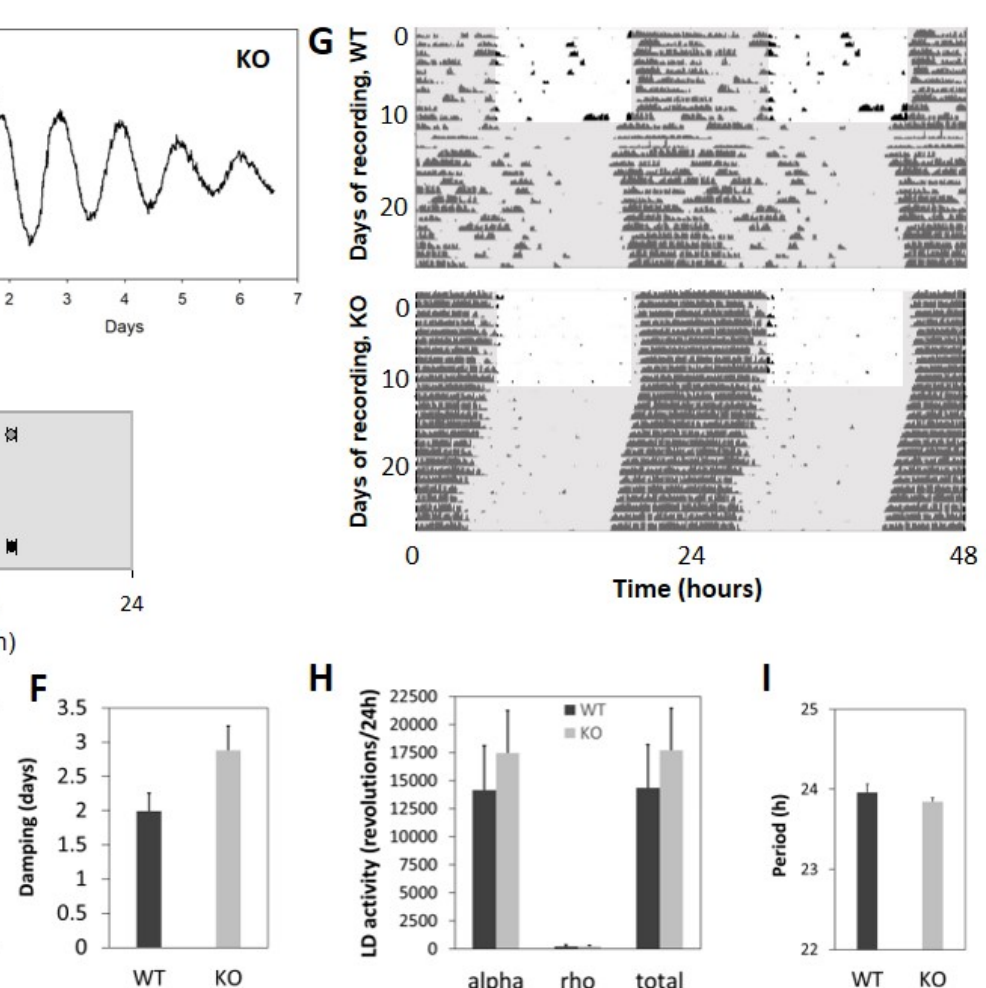

H

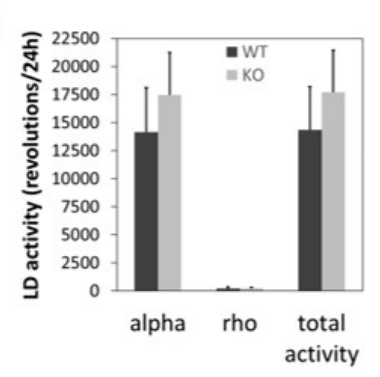

I

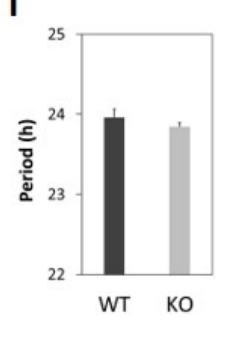

Figure 2: The cone-only retina does not affect the endogenous master clockwork

(A-F) The SCN oscillating capacity is not altered in the $\mathrm{Nrl}^{-/-}$mutant. (A) Representative PER2::LUC bioluminescence recordings (detrended data) of SCN explants from WT and $\mathrm{Nrl}^{-}$ /- animals. No genotype effect was observed in the relative rhythmic power (B), phase of first peak (C; expressed relative to the LD cycle to which animals were previously exposed), amplitude (D), period (E) and damping (F) ( $\mathrm{n}=5$ for WT, $\mathrm{n}=7$ for KO). (G-I) Actimetry recordings (wheel running) of WT and $\mathrm{Nrl}^{-/-}$mice show no genotype effect in both LD and DD conditions. (G) Representative actograms of WT (top) and KO (bottom) mice in 12h/12h LD cycle followed by constant darkness for 16 days. Grey shading indicates darkness. $(\mathrm{H})$ Quantification of activity during the night-time (alpha), day-time (rho) and total $24 \mathrm{~h}$ in LD recordings, and of the endogenous periods measured in DD (I) showed no difference between genotypes ( $\mathrm{n}=4$ for $\mathrm{WT}, \mathrm{n}=7$ for KO). Results are represented as mean \pm SEM. 


\section{Mild effects of acute light exposure}

To evaluate behavioral response to acute light exposure, WT and KO mice were first exposed to a phase-resetting protocol. Thus, animals received a 15 min light pulse with different intensities, at the beginning of the constant dark period. Light pulses of high (170-220 lux), medium (14-20 lux) or low (1.0-1.3 lux) intensities provided at projected ZT15 induced a phase-delay in the onset of activity of both WT and Nrl mutant mice (Figure 3A). The ANOVA shows a light intensity effect on phase-shifts (2-way ANOVA, $p=0.006)$, but not a genotype effect $(p=0.251)$ nor an interaction between light intensity and genotype $(p=$ 0.485) (Figure 3B). This indicates that the response to the $15 \mathrm{~min}$ light pulse was not altered in the absence of rods, at least not down to 1 lux light.

Secondly, in the negative masking protocol, a $3 \mathrm{~h}$ light pulse applied $2 \mathrm{~h}$ after the lights off inhibited locomotor activity (Figure 3C) with a significant light intensity effect $(p<0.001)$ and an interaction between light intensity and genotype $(p=0.004)$. Mutant animals indeed showed reduced masking effect at lowest light intensities $(p<0.01$ at $<1$ lux and $p<0.001$ at 1-10 lux) (Figure 3D). 

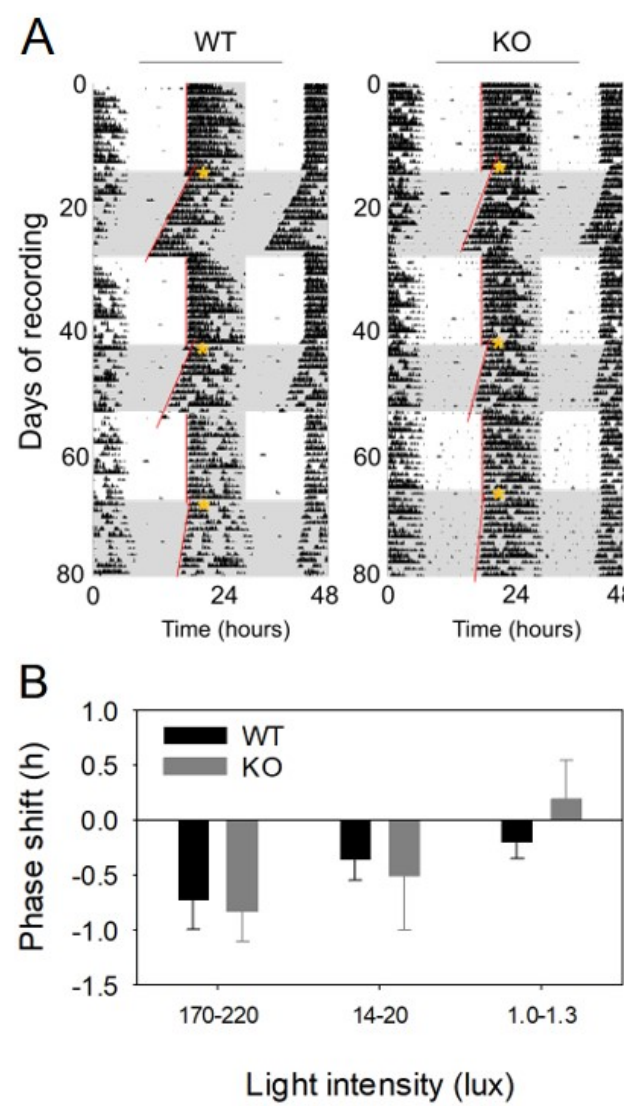

C
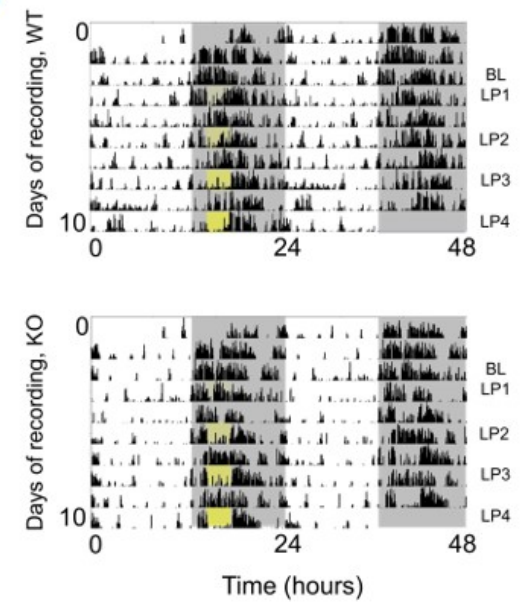

D

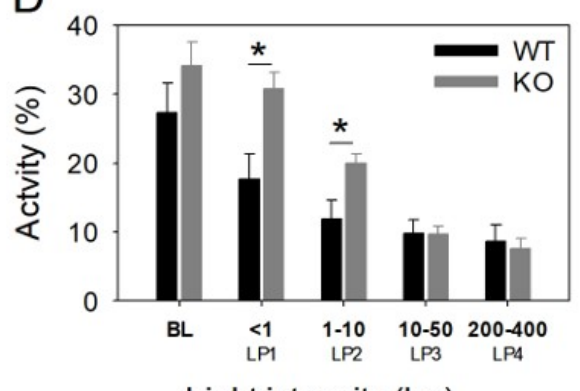

Light intensity (lux)

\section{Figure 3: Acute effects of light in Nrl-/- mice}

(A) Representative actograms of the wheel-running activity of WT (left) and KO (right) mice following exposure to 15 min light pulses of decreasing intensity given at projected ZT15 (yellow star). Fits to onset of activity used to determine phase shifts are shown in red. Intensities of the pulse are indicated on the right of actograms. (B) Phase delays decreased with light intensity (WT $\mathrm{n}=5, \mathrm{KO} \mathrm{n}=8$; 2-way ANOVA, $p=0.006$ ) but there was no genotype effect $(p=0.251)$ nor any interaction with light intensity ( $p=0.485)$. (C) Representative actograms of the general locomotor activity of WT (top) and KO (bottom) animals in the negative masking experiment when $3 \mathrm{~h}$ light pulses were provided at the beginning of the night phase (ZT14 to ZT17: yellow rectangle) every second day, with increasing light intensities. (D) Residual activity upon light exposure was expressed relative to the total activity during the preceding night $(p<0.001)$ and showed significant interaction between light intensity and genotype $(p=0.004)$ (WT $n=6, \mathrm{KO} n=7$ ). Post hoc analysis shows significant differences between genotypes for the two lowest stimuli $(p<0.01$ at $<1$ lux and $p<0.001$ at 1-10 lux). Results are represented as mean \pm SEM. $*: p<0.01$. Grey shading indicates darkness. 


\section{$\mathrm{Nrl}^{-/-}$mice do not re-entrain to phase-shifted LD cycle at low light intensity}

Animals were challenged with four successive $6 \mathrm{~h}$ phase-delayed LD cycles combined with a reduction of light intensity (100 lux, 10 lux, 1 lux, 0,1 lux) (Figure 4A, Supplementary Figure 4). WT animals were able to entrain to each shifted LD cycle at different light intensities while the KO mice needed longer time to entrain at 1 lux (jet-lag 3, $p=0.026$ ) and were not able to entrain at 0.1 lux (jet-lag 4, $p<0.001$ ) even after 50 days (Figure 4B). Subsequent exposure to total darkness (DD, 22 days) confirmed that almost all mutant animals were freerunning in the previous condition (Figure 4A and Supplementary Figure 4; data not shown). When animals were subsequently exposed to LD at 100 lux during the light phase, animals from both genotypes were able to re-entrain (Figure 4B), confirming that there was no overt loss of visual function. 

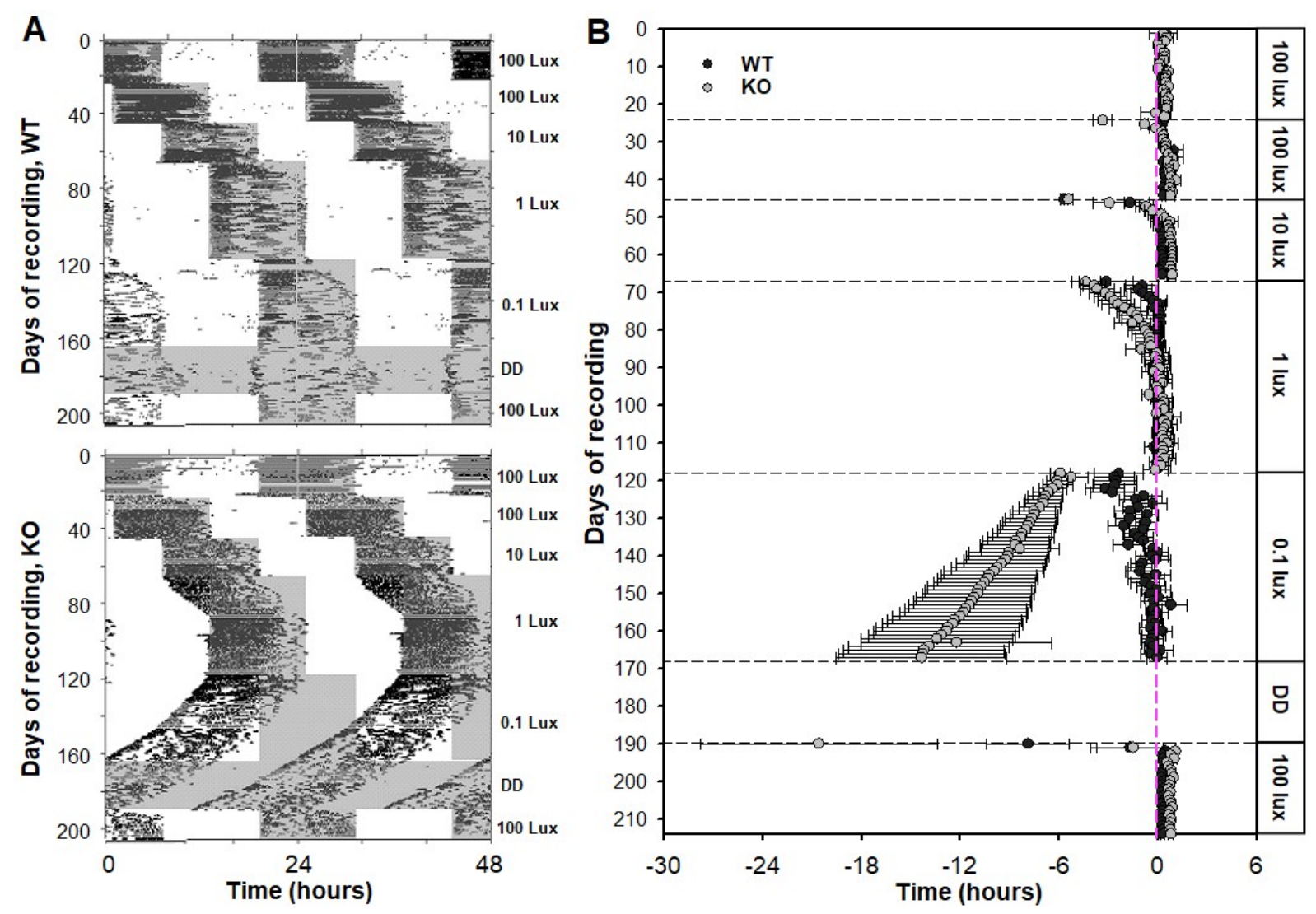

Figure 4: Loss of re-entrainment to a $6 \mathrm{~h}$ phase delay at low light intensities in the $\mathrm{Nrl}^{-/-}$ mice.

Representative actograms from WT (top) and KO (bottom) animals submitted to successive 6h delayed cycles of $12 \mathrm{~h}$ light and $12 \mathrm{~h}$ dark with decreasing intensities (indicated on the right side of actograms), then to 22 days of DD and finally again to an LD cycle at normal intensity (100 lux). Grey shading indicates darkness. (B) Onsets of activity expressed relative to ZT0 of the new LD cycle are shown for each day throughout the entrainment experiment, with intensities during the light phase or DD exposure (no data in this case) indicated on the right. $\mathrm{Nrl}^{-/-}$animals need more time to re-entrain at 1 lux $(p=0.026)$ and do not entrain at all at 0.1 $\operatorname{lux}(p=0.001)(\mathrm{n}=5$ for both $\mathrm{WT}$ and KO$)$. Results are represented as mean \pm SEM. 


\section{Major response to constant light in cone only mice}

We challenged the mice for 70 days in constant light (LL) (200 lux) (Figure 5A, Supplementary Figure 5). Both genotypes showed rhythmic free-run behaviour but 2 successive steps could be distinguished. A first transient step in which periods substantially increased in both genotypes to approximately $25.5 \mathrm{~h}$ and then a stabilized free-run in which periods decreased again, especially in the KO mice (Figure 5B). Thus, 6 out of 7 mutants had periods shorter than $24 \mathrm{~h}(23.17 \pm 0.21 \mathrm{~h}, p<0.015)$ while one mutant had a period of 24.17 h. Interestingly in this interval, whereas WT mice exhibited a drastic reduction in total locomotor activity, KO mice retained almost normal activity, 8-fold higher than in WT animals $(p=0.035)$. This difference observed in LL was also underlined by a more than 4fold higher relative rhythmic power $(p=0.028)$ in KO with respect to WT mice (Figure 5B, C), indicating absence of inhibition by light and a higher robustness of the circadian rhythm in the mutant mice. One mutant had arrhythmic locomotor activity during the last 2 weeks in LL When animals were replaced in LD to verify integrity of light responsiveness and activity, mice from both genotypes showed onsets of activity aligned with the start of dark (Figure 5A, Supplementary Figure 5) and similar mean activity ratios LD2/LD1 ( $p=0.375)$ (Figure 5D). 
A
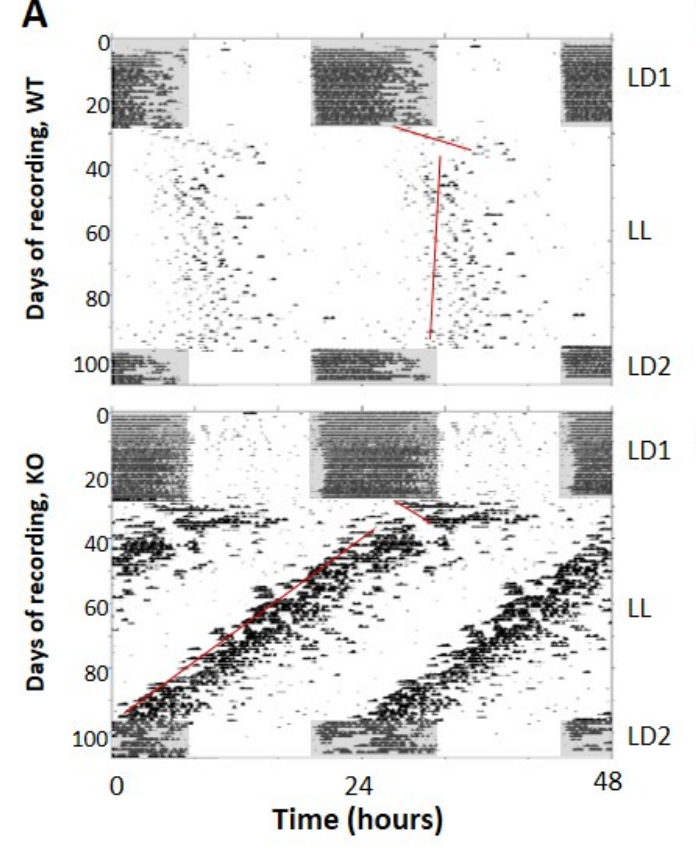

B
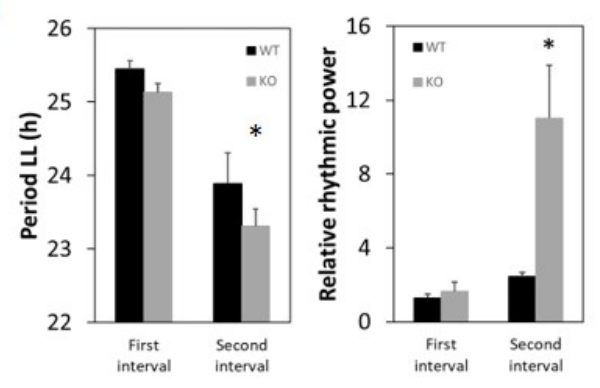

C

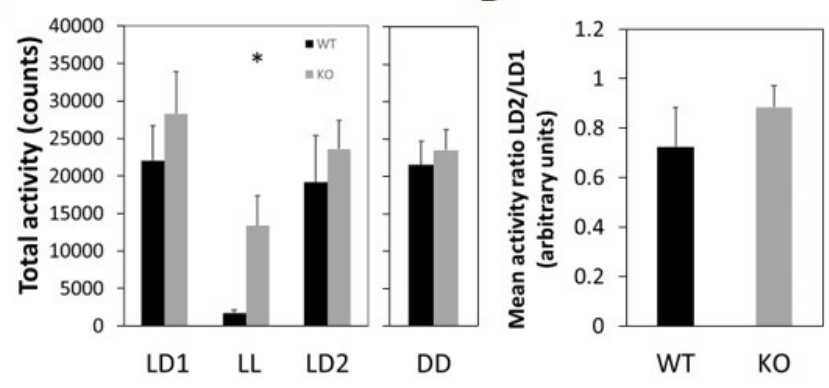

Figure 5: Cone-only mice show perturbed behaviour in constant light

(A) Representative actograms from WT (top) and KO (bottom) animals submitted to 70 days of constant light at 130 lux. Animals were previously maintained in 12h/12h LD cycle (LD1) and returned to the same lighting regime (LD2) following LL conditions. Grey shading indicates darkness. Fits to onset of activity used to determine periods are shown in red. (B) Activity pattern was separated into 2 distinctive intervals of behaviour and thus analysed separately: a first interval with increasing periods for both genotypes and a second one with reducing periods in which the mutant mice exhibited extremely low period values ( $\mathrm{n}=6$ out of 7; $p=0.015)$. Relative rhythmic power was increased in the KO during the second interval ( $p=0.028)$. (C) Total activity per cycle was measured in LL (second interval), LD1, LD2 and also compared to the DD condition from Figure 2. Significant difference between WT and mutant mice was observed for total activity specifically during LL $(p=0.035)$. Total activity did not vary for KO animals between lighting regimens $(p=0.066)$ but did for WT between LL and the other lighting conditions ( $p=0.022$ ). (D) No alterations of activity when animals return to LD, as indicated by similar mean activity ratios LD2/LD1 for WT and KO ( $p=$ 0.375) (WT $n=6, \mathrm{KO} n=7)$. Results are represented as mean \pm SEM. *: $p<0.05$. 


\section{Discussion}

In the present study we used different approaches to determine the role of cones in the circadian system. We show that photoreceptor layers lacking rods but having normal cone and cone-pathway contain a molecular machinery characteristic of a functional clockwork and likely contribute, together with the inner and ganglion cell layers, to the overall clock rhythmicity in the retina. We bring evidence that the $\mathrm{Nrl}^{-/-}$retina also displays novel distinctive properties regarding light impact on the central clock, providing new insight into the role of cones in the circadian system.

Rhythmic functions in mammalian cones have been only poorly documented [13, 47-50], likely because of the scarcity of this cell type in nocturnal rodents [18, 19]. To circumvent this limitation, we used the $\mathrm{Nrl}^{-/-}$animal model in which all rods are replaced by cones [20, 51]. These photoreceptors were previously shown to have major characteristics of native S-cones regarding morphology, molecular content, nuclear architecture and light response [20, 51-53] and constitute an adequate model to question the properties of cones without the interference from rods. Moreover, and unlike what was shown in other models with impaired rod phototransduction pathway $[54,55]$ these retinas show no sign of alteration of other cellular populations such as dopaminergic amacrine cells or ipRGCs, which are known to contribute to clock properties in the retina $[8,13]$.

Cellular localization of the circadian clock in the mammalian retina is still a matter of debate. The literature agrees on a main contribution from the inner retina [9, 44] and several reports exclude rod-type photoreceptors from the circadian network [13, 56, 57] although the presence of sustained clock gene rhythms in rods has been suggested elsewhere [8-10, 58]. Upon immunofluorescence analysis of clock protein factors, cones appeared the most evident cell-autonomous clock in the mouse retina [13]. In agreement with this study, we here describe robust rhythms in expression of clock genes from the main (Bmal1, Per1, Per3) and 
secondary (Rev-Erb $\alpha)$ loops of the well described molecular machinery [59] in $\mathrm{Nrl}^{-/-}$ photoreceptor layers laser-microdissected throughout the $24 \mathrm{~h}$ cycle in constant dark condition. However, unlike what was described for immunostained clock factors, their mRNAs show distinct phases, as observed at the level of the whole retina [44], which might be due to the enrichment in S- versus $\mathrm{M}$-cones in the $\mathrm{KO}$ retinas or suggest posttranscriptional regulation of clock factors. We previously described that cones are the photoreceptor site of robust oscillations in Aanat (the enzyme responsible for melatonin rhythm) expression by using a diurnal, cone-rich rodent, Arvicanthis ansorgei [11, 47]. Besides, circadian rhythms in cone-specific genes have essentially been investigated in chicken [60, 61] and zebrafish [62]. In particular, robust rhythms in phototransduction genes in zebrafish cones appear driven by key transcription factors (Neurod, Crx) themselves regulated by the clock [63]. In our study, cones express major phototransduction elements in a rhythmic manner with high amplitudes but we did not detect any rhythm in Crx expression, indicating that in mammalian cones phototransduction elements retain clock regulation but with mechanisms distinct from the zebrafish. Importantly, when isolated by vibratomesectioning of fresh retinas, cone layers express sustained rhythms with a specific period, distinct from the period measured in photoreceptor layers from control mice. This observation probably reflects the differences in clock machinery and associated signalling occurring in rods (97\% of photoreceptors in WT) versus cones. It might also reflect a difference in coupling strength within the respective photoreceptor populations, as previously described in the retina [9]. Communication through gap junctions might be reduced in the S-cone enriched photoreceptor layers of the KO, since expression of connexion 36 was shown to be absent in this cone population in mammals [64]. This might be responsible for the increased period in the KO [9]. Taken together with our demonstration of rhythmic phagocytosis of cone outer segments [21] our data strongly suggest the presence of a functional, autonomous circadian clock within cones. 
To get more insight into the contribution of cones to the retinal clock network we turned to an imaging-coupled bioluminescence approach. Bioluminescence imaging of transversal retinal sections shows rhythmic Per2 expression throughout the (cone) outer nuclear layer, confirming that cones contribute to the retinal clock network, even if this is low when compared to the signal displayed by the ganglion cell and inner nuclear layers. The observation that the three cell layers of the retina show similar, $>25 \mathrm{~h}$ periods further fits with our previously described model of multi-oscillatory retinal clock [9]. By contrast, when considering bioluminescence in whole retinal explants, the replacement of rods by cones leads to substantial reduction in baseline and amplitude without any effect on the period, rhythmic power and damping rate. This result is unexpected in regard of recent literature reporting the absence of clock in rods $[56,57]$ and does not exclude that the rod population does contain a clock and contributes to the oscillator network in whole retinas. It cannot be excluded, however, that the defects in the $\mathrm{Nrl}^{-/-}$retinas reflect the health status of their photoreceptors, even if sampling was done prior to their reported apoptosis period [65].

The involvement of cones in circadian functions has been documented. A role in synchronisation of the SCN has been demonstrated for both green cones [29] and S-cones [30, $31,33,66]$. However, the contribution of cones to the effects of white ambient lighting on circadian properties and more generally non-image forming vision, has been evaluated with a limited variety of visually impaired mouse models. We used a battery of behavioural tests [67] to investigate this question with the cone-only $\mathrm{Nrl}^{-/-}$model. Our data were generated in indoor laboratory conditions comprising full spectrum visual light in agreement with the capacity of the KO model to respond to photopic light similar to the WT upon electroretinography recording (Supplementary Figure 2). We observed that the high number of cones does not provide any increased response capacity of the circadian system to the 
diverse light stimulation paradigms used here. This result corroborates previous discussion in the field, suggesting that the light adaptation properties of cones preclude their participation in the input of long light exposure to the circadian system, including phase shift experiments [26, 28]. Indeed, no defect was detected in $\mathrm{Nrl}^{-/-}$mice under the phase shift paradigm (as also seen in [45]). By contrast, our model rather displays some features typical of rodless animals, such as reduced capacity to shift at low light intensity ( 1 or 0.1 lux) in a jet-lag experiment, as previously observed with the Gnat1 ${ }^{-/-}$model [26]. Physiological features of rodless retina are also reflected in dopamine metabolism (Supplementary Figure 1D), with the loss of daily rhythm of DOPAC generation in $\mathrm{KO}$ retinas $[46,68]$ as previously described for the rds strain. The discrepancy between the results from light pulse and the jet-lag experiments might be due to the fact that the threshold levels required for entrainment constitute a more sensitive test of deficit in entrainment than phase shift following a light pulse [69].

Rats or mice with outer retinal impairment were repeatedly reported to exhibit total loss of positive masking by light and (consequently) enhanced inhibition of locomotor activity (negative masking), especially at low light intensities [70-72]. By contrast, melanopsin phototransduction appears indispensable for negative masking [73]. Using monochromatic light, Thompson et al. also provide evidence that cones (short- and medium-wavelength sensitive) contribute to negative masking and influence its dynamic range [74]. In the present study, the $\mathrm{Nrl}^{-/-}$animals show reduced negative masking behaviour specifically at low light intensities (between 0.5 and 10 lux), despite a normal ipRGC population and unlike most rodless mice. The discrepancy between this result and the literature might be explained by the fact that we used global activity recordings and not wheel running activity. Indeed, positive masking might be more pronounced when using wheel running activity and hence introduce a confounding effect (increased negative masking in rodless animals) at low light intensity. Furthermore, some data also indicate that rods contribute, at least transiently, to negative 
masking at light intensities too low to excite ipRGC [75]. Thus, the behaviour triggered in the $\mathrm{Nrl}^{-/-}$animals by acute light stimulation probably reflects the combined absence of rods and integrity of ipRGC.

Increase of the endogenous period in constant light has also been partly attributed to rod signalling [26, 28] and requires the integrity of ipRGC [23]. In our experiments we observed that the free running periods in LL were first increased to a similar extent for both the WT and mutant mice, suggesting that mechanisms distinct of the rod-pathway are involved. However, periods then decreased, with WT reaching a mean value around $24 \mathrm{~h}$ and the mutants rather lower periods (23.25 h on average). In addition, KO mice retained high level of activity in constant light, indicating loss of masking or of light aversion, a feature which is also shared with mice devoid of ipRGC [23] and has been proposed to mainly involve these cells [71] but also other photosensitive systems in the retina [76]. Thus, the exact mechanism underlying this phenotype here remains to be determined. Short free-running period values have been rarely described in LL, except in Per2 clock gene mutants of different backgrounds [77-79]. The phenotype in the $\mathrm{Nrl}^{-/-}$mice could be explained by distinct hypotheses: 1 , their high wheel running activity in LL might feedback on the clock and induce period shortening [80]; 2, the sustained activity might simply counteract the effects of (constant) light on neuronal activity in the SCN and counterbalance the period-lengthening mechanism [81]; 3, cone abundance could trigger another, yet unknown signalling towards the central clock. Identification of the mechanisms by which excess of cones alters properties of the circadian system will require further investigation.

In conclusion, by using the $\mathrm{Nrl}^{-/-}$cone-only mouse model we provide compelling evidence that cones contain a circadian clock part of the retinal oscillating network. Our data confirm 
the interest of visual system mutants in the understanding of retinal pathways regulating the central clock. Exposure of $\mathrm{Nrl}^{-/-}$mice to specific experimental paradigms highlighted their particularities, namely loss of entrainment and negative masking induced by the absence of rods and, importantly, altered behaviour in constant light, specific to the enlarged cone population. Thus, cones are important players in the circadian system with distinctive properties and contributions, both as light sensors for the central clock and as elements of the retinal circadian system. 


\section{References}

1. Hastings MH, Maywood ES, Brancaccio M (2019) The Mammalian Circadian Timing System and the Suprachiasmatic Nucleus as Its Pacemaker. Biology (Basel) 8 https://doi.org/10.3390/biology8010013.

2. Nelson RJ, Zucker I (1981) Absence of extraocular photoreception in diurnal and nocturnal rodents exposed to direct sunlight. Comparative Biochemistry and Physiology Part A: Physiology 69: 145-148. https://doi.org/10.1016/03009629(81)90651-4.

3. Yamazaki S, Goto M, Menaker M (1999) No evidence for extraocular photoreceptors in the circadian system of the Syrian hamster. J Biol Rhythms 14: 197-201. https://doi.org/10.1177/074873099129000605.

4. Tosini G, Menaker M (1996) Circadian rhythms in cultured mammalian retina. Science 272: 419-21. https://doi.org/10.1126/science.272.5260.419.

5. Felder-Schmittbuhl MP, Buhr ED, Dkhissi-Benyahya O, Hicks D, Peirson SN, Ribelayga CP, Sandu C, Spessert R, Tosini G (2018) Ocular Clocks: Adapting Mechanisms for Eye Functions and Health. Invest Ophthalmol Vis Sci 59: 4856-4870. https://doi.org/10.1167/iovs.18-24957.

6. McMahon DG, Iuvone PM, Tosini G (2014) Circadian organization of the mammalian retina: from gene regulation to physiology and diseases. Prog Retin Eye Res 39: 5876. https://doi.org/10.1016/j.preteyeres.2013.12.001.

7. Felder-Schmittbuhl MP, Calligaro H, Dkhissi-Benyahya O (2017) The retinal clock in mammals: role in health and disease. Chronophysiology Ther. 7: 33-45. https://doi.org/doi:10.2147/CPT.S115251.

8. Dkhissi-Benyahya O, Coutanson C, Knoblauch K, Lahouaoui H, Leviel V, Rey C, Bennis M, Cooper HM (2013) The absence of melanopsin alters retinal clock function and dopamine regulation by light. Cell Mol Life Sci 70: 3435-47.

https://doi.org/10.1007/s00018-013-1338-9. 
9. Jaeger C, Sandu C, Malan A, Mellac K, Hicks D, Felder-Schmittbuhl MP (2015) Circadian organization of the rodent retina involves strongly coupled, layer-specific oscillators. FASEB J 29: 1493-504. https://doi.org/10.1096/fj.14-261214.

10. Sandu C, Hicks D, Felder-Schmittbuhl MP (2011) Rat photoreceptor circadian oscillator strongly relies on lighting conditions. Eur J Neurosci 34: 507-16. https://doi.org/10.1111/j.1460-9568.2011.07772.x.

11. Gianesini C, Clesse D, Tosini G, Hicks D, Laurent V (2015) Unique Regulation of the Melatonin Synthetic Pathway in the Retina of Diurnal Female Arvicanthis ansorgei (Rodentia). Endocrinology 156: 3292-308. https://doi.org/10.1210/EN.2015-1267.

12. Niki T, Hamada T, Ohtomi M, Sakamoto K, Suzuki S, Kako K, Hosoya Y, Horikawa K, Ishida N (1998) The localization of the site of arylalkylamine N-acetyltransferase circadian expression in the photoreceptor cells of mammalian retina. Biochem Biophys Res Commun 248: 115-20. https://doi.org/10.1006/bbrc.1998.8916.

13. Liu X, Zhang Z, Ribelayga CP (2012) Heterogeneous expression of the core circadian clock proteins among neuronal cell types in mouse retina. PLoS One 7: e50602. https://doi.org/10.1371/journal.pone.0050602.

14. Applebury ML, Antoch MP, Baxter LC, Chun LL, Falk JD, Farhangfar F, Kage K, Krzystolik MG, Lyass LA, Robbins JT (2000) The murine cone photoreceptor: a single cone type expresses both $\mathrm{S}$ and $\mathrm{M}$ opsins with retinal spatial patterning. Neuron 27: 513-23. https://doi.org/10.1016/s0896-6273(00)00062-3.

15. Rohlich P, van Veen T, Szel A (1994) Two different visual pigments in one retinal cone cell. Neuron 13: 1159-66. https://doi.org/10.1016/0896-6273(94)90053-1.

16. Szel A, Rohlich P, Caffe AR, Juliusson B, Aguirre G, Van Veen T (1992) Unique topographic separation of two spectral classes of cones in the mouse retina. J Comp Neurol 325: 327-42. https://doi.org/10.1002/cne.903250302.

17. Haverkamp S, Wassle H, Duebel J, Kuner T, Augustine GJ, Feng G, Euler T (2005) The primordial, blue-cone color system of the mouse retina. J Neurosci 25: 5438-45. https://doi.org/10.1523/JNEUROSCI.1117-05.2005.

18. Jeon CJ, Strettoi E, Masland RH (1998) The major cell populations of the mouse retina. J Neurosci 18: 8936-46. 
19. Szel A, Rohlich P (1992) Two cone types of rat retina detected by anti-visual pigment antibodies. Exp Eye Res 55: 47-52. https://doi.org/10.1016/0014-4835(92)90090-f.

20. Mears AJ, Kondo M, Swain PK, Takada Y, Bush RA, Saunders TL, Sieving PA, Swaroop A (2001) Nrl is required for rod photoreceptor development. Nat Genet 29: 447-52. https://doi.org/10.1038/ng774.

21. Krigel A, Felder-Schmittbuhl MP, Hicks D (2010) Circadian-clock driven cone-like photoreceptor phagocytosis in the neural retina leucine zipper gene knockout mouse. Mol Vis 16: 2873-81.

22. Wenzel A, von Lintig J, Oberhauser V, Tanimoto N, Grimm C, Seeliger MW (2007) RPE65 is essential for the function of cone photoreceptors in NRL-deficient mice. Invest Ophthalmol Vis Sci 48: 534-42. https://doi.org/10.1167/iovs.06-0652.

23. Goz D, Studholme K, Lappi DA, Rollag MD, Provencio I, Morin LP (2008) Targeted destruction of photosensitive retinal ganglion cells with a saporin conjugate alters the effects of light on mouse circadian rhythms. PLoS One 3: e3153. https://doi.org/10.1371/journal.pone.0003153.

24. Guler AD, Ecker JL, Lall GS, Haq S, Altimus CM, Liao HW, Barnard AR, Cahill H, Badea TC, Zhao H, Hankins MW, Berson DM, Lucas RJ, Yau KW, Hattar S (2008) Melanopsin cells are the principal conduits for rod-cone input to non-image-forming vision. Nature 453: 102-5. https://doi.org/10.1038/nature06829.

25. Hatori M, Le H, Vollmers C, Keding SR, Tanaka N, Buch T, Waisman A, Schmedt C, Jegla T, Panda S (2008) Inducible ablation of melanopsin-expressing retinal ganglion cells reveals their central role in non-image forming visual responses. PLoS One 3: e2451. https://doi.org/10.1371/journal.pone.0002451.

26. Altimus CM, Guler AD, Alam NM, Arman AC, Prusky GT, Sampath AP, Hattar S (2010) Rod photoreceptors drive circadian photoentrainment across a wide range of light intensities. Nat Neurosci 13: 1107-12. https://doi.org/10.1038/nn.2617.

27. Boudard DL, Mendoza J, Hicks D (2009) Loss of photic entrainment at low illuminances in rats with acute photoreceptor degeneration. Eur J Neurosci 30: 152736. https://doi.org/10.1111/j.1460-9568.2009.06935.x.

28. Lall GS, Revell VL, Momiji H, Al Enezi J, Altimus CM, Guler AD, Aguilar C, Cameron MA, Allender S, Hankins MW, Lucas RJ (2010) Distinct contributions of 
rod, cone, and melanopsin photoreceptors to encoding irradiance. Neuron 66: 417-28. https://doi.org/10.1016/j.neuron.2010.04.037.

29. Dkhissi-Benyahya O, Gronfier C, De Vanssay W, Flamant F, Cooper HM (2007)

Modeling the role of mid-wavelength cones in circadian responses to light. Neuron 53:

677-87. https://doi.org/10.1016/j.neuron.2007.02.005.

30. van Diepen HC, Ramkisoensing A, Peirson SN, Foster RG, Meijer JH (2013)

Irradiance encoding in the suprachiasmatic nuclei by rod and cone photoreceptors.

FASEB J 27: 4204-12. https://doi.org/10.1096/fj.13-233098.

31. van Oosterhout F, Fisher SP, van Diepen HC, Watson TS, Houben T, VanderLeest HT, Thompson S, Peirson SN, Foster RG, Meijer JH (2012) Ultraviolet light provides a major input to non-image-forming light detection in mice. Curr Biol 22: 1397-402. https://doi.org/10.1016/j.cub.2012.05.032.

32. Mouland JW, Martial F, Watson A, Lucas RJ, Brown TM (2019) Cones Support Alignment to an Inconsistent World by Suppressing Mouse Circadian Responses to the Blue Colors Associated with Twilight. Curr Biol 29: 4260-4267 e4. https://doi.org/10.1016/j.cub.2019.10.028.

33. Walmsley L, Hanna L, Mouland J, Martial F, West A, Smedley AR, Bechtold DA, Webb AR, Lucas RJ, Brown TM (2015) Colour as a signal for entraining the mammalian circadian clock. PLoS Biol 13: e1002127. https://doi.org/10.1371/journal.pbio.1002127.

34. Yoo SH, Yamazaki S, Lowrey PL, Shimomura K, Ko CH, Buhr ED, Siepka SM, Hong HK, Oh WJ, Yoo OJ, Menaker M, Takahashi JS (2004)

PERIOD2::LUCIFERASE real-time reporting of circadian dynamics reveals persistent circadian oscillations in mouse peripheral tissues. Proc Natl Acad Sci U S A 101: 5339-46. https://doi.org/10.1073/pnas.0308709101.

35. Hellemans J, Mortier G, De Paepe A, Speleman F, Vandesompele J (2007) qBase relative quantification framework and software for management and automated analysis of real-time quantitative PCR data. Genome Biol 8: R19. https://doi.org/10.1186/gb-2007-8-2-r19. 
36. Klarsfeld A, Leloup JC, Rouyer F (2003) Circadian rhythms of locomotor activity in Drosophila. Behav Processes 64: 161-175. https://doi.org/10.1016/s03766357(03)00133-5.

37. Mendoza J, Graff C, Dardente H, Pevet P, Challet E (2005) Feeding cues alter clock gene oscillations and photic responses in the suprachiasmatic nuclei of mice exposed to a light/dark cycle. J Neurosci 25: 1514-22.

https://doi.org/10.1523/JNEUROSCI.4397-04.2005.

38. Salaberry NL, Hamm H, Felder-Schmittbuhl MP, Mendoza J (2019) A suprachiasmatic-independent circadian clock(s) in the habenula is affected by Per gene mutations and housing light conditions in mice. Brain Struct Funct 224: 19-31. https://doi.org/10.1007/s00429-018-1756-4.

39. Nelson W, Tong YL, Lee JK, Halberg F (1979) Methods for cosinor-rhythmometry. Chronobiologia 6: 305-23.

40. King DP, Takahashi JS (2000) Molecular genetics of circadian rhythms in mammals. Annu Rev Neurosci 23: 713-42. https://doi.org/10.1146/annurev.neuro.23.1.713.

41. Welsh DK, Takahashi JS, Kay SA (2010) Suprachiasmatic nucleus: cell autonomy and network properties. Annu Rev Physiol 72: 551-77. https://doi.org/10.1146/annurevphysiol-021909-135919.

42. Noguchi T, Michihata T, Nakamura W, Takumi T, Shimizu R, Yamamoto M, Ikeda M, Ohmiya Y, Nakajima Y (2010) Dual-color luciferase mouse directly demonstrates coupled expression of two clock genes. Biochemistry 49: 8053-61. https://doi.org/10.1021/bi100545h.

43. Oishi K, Sakamoto K, Okada T, Nagase T, Ishida N (1998) Antiphase circadian expression between BMAL1 and period homologue mRNA in the suprachiasmatic nucleus and peripheral tissues of rats. Biochem Biophys Res Commun 253: 199-203. https://doi.org/10.1006/bbrc.1998.9779.

44. Ruan GX, Allen GC, Yamazaki S, McMahon DG (2008) An autonomous circadian clock in the inner mouse retina regulated by dopamine and GABA. PLoS Biol 6: e249. https://doi.org/10.1371/journal.pbio.0060249.

45. Calligaro H, Coutanson C, Najjar RP, Mazzaro N, Cooper HM, Haddjeri N, FelderSchmittbuhl MP, Dkhissi-Benyahya O (2019) Rods contribute to the light-induced 
phase shift of the retinal clock in mammals. PLoS Biol 17: e2006211.

https://doi.org/10.1371/journal.pbio.2006211.

46. Nir I, Iuvone PM (1994) Alterations in light-evoked dopamine metabolism in dystrophic retinas of mutant rds mice. Brain Res 649: 85-94.

https://doi.org/10.1016/0006-8993(94)91051-0.

47. Bobu C, Sandu C, Laurent V, Felder-Schmittbuhl MP, Hicks D (2013) Prolonged light exposure induces widespread phase shifting in the circadian clock and visual pigment gene expression of the Arvicanthis ansorgei retina. Mol Vis 19: 1060-73.

48. Sakamoto K, Liu C, Kasamatsu M, Iuvone PM, Tosini G (2006) Intraocular injection of kainic acid does not abolish the circadian rhythm of arylalkylamine Nacetyltransferase mRNA in rat photoreceptors. Mol Vis 12: 117-24.

49. Storch KF, Paz C, Signorovitch J, Raviola E, Pawlyk B, Li T, Weitz CJ (2007) Intrinsic circadian clock of the mammalian retina: importance for retinal processing of visual information. Cell 130: 730-741. https://doi.org/10.1016/j.cell.2007.06.045.

50. von Schantz M, Lucas RJ, Foster RG (1999) Circadian oscillation of photopigment transcript levels in the mouse retina. Brain Res Mol Brain Res 72: 108-14. https://doi.org/S0169328X99002090 [pii].

51. Akimoto M, Cheng H, Zhu D, Brzezinski JA, Khanna R, Filippova E, Oh EC, Jing Y, Linares JL, Brooks M, Zareparsi S, Mears AJ, Hero A, Glaser T, Swaroop A (2006) Targeting of GFP to newborn rods by Nrl promoter and temporal expression profiling of flow-sorted photoreceptors. Proc Natl Acad Sci U S A 103: 3890-5. https://doi.org/10.1073/pnas.0508214103.

52. Daniele LL, Lillo C, Lyubarsky AL, Nikonov SS, Philp N, Mears AJ, Swaroop A, Williams DS, Pugh EN, Jr. (2005) Cone-like morphological, molecular, and electrophysiological features of the photoreceptors of the Nrl knockout mouse. Invest Ophthalmol Vis Sci 46: 2156-67. https://doi.org/10.1167/iovs.04-1427.

53. Nikonov SS, Daniele LL, Zhu X, Craft CM, Swaroop A, Pugh EN, Jr. (2005) Photoreceptors of Nrl -/- mice coexpress functional S- and M-cone opsins having distinct inactivation mechanisms. J Gen Physiol 125: 287-304. https://doi.org/10.1085/jgp.200409208. 
54. Munteanu T, Noronha KJ, Leung AC, Pan S, Lucas JA, Schmidt TM (2018) Lightdependent pathways for dopaminergic amacrine cell development and function. Elife 7 https://doi.org/10.7554/eLife.39866.

55. Sakamoto K, Liu C, Tosini G (2004) Classical photoreceptors regulate melanopsin mRNA levels in the rat retina. J Neurosci 24: 9693-7.

https://doi.org/10.1523/JNEUROSCI.2556-04.2004.

56. Baba K, Piano I, Lyuboslavsky P, Chrenek MA, Sellers JT, Zhang S, Gargini C, He L, Tosini G, Iuvone PM (2018) Removal of clock gene Bmal1 from the retina affects retinal development and accelerates cone photoreceptor degeneration during aging. Proc Natl Acad Sci U S A 115: 13099-13104. https://doi.org/10.1073/pnas.1808137115.

57. Ruan GX, Zhang DQ, Zhou T, Yamazaki S, McMahon DG (2006) Circadian organization of the mammalian retina. Proc Natl Acad Sci U S A 103: 9703-8. https://doi.org/10.1073/pnas.0601940103.

58. Tosini G, Davidson AJ, Fukuhara C, Kasamatsu M, Castanon-Cervantes O (2007) Localization of a circadian clock in mammalian photoreceptors. FASEB J 21: 386671. https://doi.org/10.1096/fj.07-8371com.

59. Takahashi JS (2017) Transcriptional architecture of the mammalian circadian clock. Nat Rev Genet 18: 164-179. https://doi.org/10.1038/nrg.2016.150.

60. Haque R, Ali FG, Biscoglia R, Abey J, Weller J, Klein D, Iuvone PM (2010) CLOCK and NPAS2 have overlapping roles in the circadian oscillation of arylalkylamine Nacetyltransferase mRNA in chicken cone photoreceptors. J Neurochem 113: 1296-306. https://doi.org/10.1111/j.1471-4159.2010.06698.x.

61. Pierce ME, Sheshberadaran H, Zhang Z, Fox LE, Applebury ML, Takahashi JS (1993) Circadian regulation of iodopsin gene expression in embryonic photoreceptors in retinal cell culture. Neuron 10: 579-84. https://doi.org/10.1016/0896-6273(93)90161j.

62. Li P, Chaurasia SS, Gao Y, Carr AL, Iuvone PM, Li L (2008) CLOCK is required for maintaining the circadian rhythms of Opsin mRNA expression in photoreceptor cells. J Biol Chem 283: 31673-8. https://doi.org/10.1074/jbc.M803875200. 
63. Laranjeiro R, Whitmore D (2014) Transcription factors involved in retinogenesis are co-opted by the circadian clock following photoreceptor differentiation. Development 141: 2644-56. https://doi.org/10.1242/dev.104380.

64. Li W, DeVries SH (2004) Separate blue and green cone networks in the mammalian retina. Nat Neurosci 7: 751-6. https://doi.org/10.1038/nn1275.

65. Roger JE, Ranganath K, Zhao L, Cojocaru RI, Brooks M, Gotoh N, Veleri S, Hiriyanna A, Rachel RA, Campos MM, Fariss RN, Wong WT, Swaroop A (2012)

Preservation of cone photoreceptors after a rapid yet transient degeneration and remodeling in cone-only Nrl-/- mouse retina. J Neurosci 32: 528-41. https://doi.org/10.1523/JNEUROSCI.3591-11.2012.

66. Provencio I, Foster RG (1995) Circadian rhythms in mice can be regulated by photoreceptors with cone-like characteristics. Brain Res 694: 183-90. https://doi.org/10.1016/0006-8993(95)00694-l.

67. Hughes S, Jagannath A, Hankins MW, Foster RG, Peirson SN (2015) Photic regulation of clock systems. Methods Enzymol 552: 125-43. https://doi.org/10.1016/bs.mie.2014.10.018.

68. Perez-Fernandez V, Milosavljevic N, Allen AE, Vessey KA, Jobling AI, Fletcher EL, Breen PP, Morley JW, Cameron MA (2019) Rod Photoreceptor Activation Alone Defines the Release of Dopamine in the Retina. Curr Biol 29: 763-774 e5. https://doi.org/10.1016/j.cub.2019.01.042.

69. Mrosovsky N (2003) Contribution of classic photoreceptors to entrainment. J Comp Physiol A Neuroethol Sens Neural Behav Physiol 189: 69-73. https://doi.org/10.1007/s00359-002-0378-7.

70. Mrosovsky N, Foster RG, Salmon PA (1999) Thresholds for masking responses to light in three strains of retinally degenerate mice. J Comp Physiol A 184: 423-8. https://doi.org/10.1007/s003590050341.

71. Thompson S, Recober A, Vogel TW, Kuburas A, Owens JA, Sheffield VC, Russo AF, Stone EM (2010) Light aversion in mice depends on nonimage-forming irradiance detection. Behav Neurosci 124: 821-7. https://doi.org/10.1037/a0021568.

72. Thompson S, Stasheff SF, Hernandez J, Nylen E, East JS, Kardon RH, Pinto LH, Mullins RF, Stone EM (2011) Different inner retinal pathways mediate rod-cone input 
in irradiance detection for the pupillary light reflex and regulation of behavioral state in mice. Invest Ophthalmol Vis Sci 52: 618-23. https://doi.org/10.1167/iovs.10-6146.

73. Mrosovsky N, Hattar S (2003) Impaired masking responses to light in melanopsinknockout mice. Chronobiol Int 20: 989-99. https://doi.org/10.1081/cbi-120026043.

74. Thompson S, Foster RG, Stone EM, Sheffield VC, Mrosovsky N (2008) Classical and melanopsin photoreception in irradiance detection: negative masking of locomotor activity by light. Eur J Neurosci 27: 1973-9. https://doi.org/10.1111/j.14609568.2008.06168.x.

75. Butler MP, Silver R (2011) Divergent photic thresholds in the non-image-forming visual system: entrainment, masking and pupillary light reflex. Proc Biol Sci 278: 74550. https://doi.org/10.1098/rspb.2010.1509.

76. Semo M, Gias C, Ahmado A, Sugano E, Allen AE, Lawrence JM, Tomita H, Coffey PJ, Vugler AA (2010) Dissecting a role for melanopsin in behavioural light aversion reveals a response independent of conventional photoreception. PLoS One 5: e15009. https://doi.org/10.1371/journal.pone.0015009.

77. Pendergast JS, Friday RC, Yamazaki S (2010) Photic entrainment of period mutant mice is predicted from their phase response curves. J Neurosci 30: 12179-84. https://doi.org/10.1523/JNEUROSCI.2607-10.2010.

78. Spoelstra K, Daan S (2008) Effects of constant light on circadian rhythmicity in mice lacking functional cry genes: dissimilar from per mutants. J Comp Physiol A Neuroethol Sens Neural Behav Physiol 194: 235-42. https://doi.org/10.1007/s00359007-0301-3.

79. Steinlechner S, Jacobmeier B, Scherbarth F, Dernbach H, Kruse F, Albrecht U (2002) Robust circadian rhythmicity of Per1 and Per2 mutant mice in constant light, and dynamics of Per1 and Per2 gene expression under long and short photoperiods. J Biol Rhythms 17: 202-9. https://doi.org/10.1177/074873040201700303.

80. Edgar DM, Martin CE, Dement WC (1991) Activity feedback to the mammalian circadian pacemaker: influence on observed measures of rhythm period length. J Biol Rhythms 6: 185-99. https://doi.org/10.1177/074873049100600301. 
bioRxiv preprint doi: https://doi.org/10.1101/2020.09.15.297879; this version posted June 8, 2021. The copyright holder for this preprint

(which was not certified by peer review) is the author/funder, who has granted bioRxiv a license to display the preprint in perpetuity. It is made available under aCC-BY 4.0 International license.

81. Schaap J, Meijer JH (2001) Opposing effects of behavioural activity and light on neurons of the suprachiasmatic nucleus. Eur J Neurosci 13: 1955-62.

https://doi.org/10.1046/j.0953-816x.2001.01561.x. 